This is the peer reviewed version of the following article: Corporal-Lodangco, I. L. and Leslie, L. M. (2017), Climatology of Philippine tropical cyclone activity: 1945-2011. Int. J. Climatol., 37: 3525-3539, which has been published in final form at https://doi.org/10.1002/joc.4931. This article may be used for non-commercial purposes in accordance with Wiley Terms and Conditions for Self-Archiving. 


\title{
Climatology of Philippine Tropical Cyclone Activity: 1945-2011
}

Short title: Philippine Tropical Cyclone Climatology

\author{
Irenea L. Corporal-Lodangco ${ }^{a}$, Lance M. Leslie ${ }^{a}$
}

${ }^{\mathrm{a}} \mathrm{School}$ of Meteorology, University of Oklahoma, Norman, Oklahoma

Submitted to International Journal of Climatology

November 17, 2015

Revised version submitted August 16, 2016

\section{Corresponding author:}

Irenea L. Corporal-Lodangco, School of Meteorology, University of Oklahoma, Norman, Oklahoma, USA

E-mail: ireneacl@,ou.edu

Tel.: 405-620-5893

Fax: 405-325-7689 


\section{ABSTRACT}

The Philippine region occupies the southwestern Western North Pacific (WNP) Ocean, between $5^{\circ} \mathrm{N}-25^{\circ} \mathrm{N}$ and $115^{\circ} \mathrm{E}-135^{\circ} \mathrm{E}$. About $70 \%$ of WNP tropical cyclones (TCs) formed in or entered the Philippine region during 1945-2011. Here, a climatology of Philippine TC metrics is developed, including mean annual frequencies, landfalls, TC days, season lengths, season earliest and latest start/end dates, genesis locations, and tracks. Two distinct TC seasons, the less active (LAS; January 1-May 31) and more active (MAS; June 1-December 31) seasons, are evident. Philippine TC annual median LAS frequency is 2 (interquartile range (IQR) is 2); median landfalling frequency is 1 . The annual median MAS frequency is 15 (IQR is 4.5), and median landfalling frequency is 6 . About $55 \%$ of Philippine TCs reach typhoon (TY) intensity. The interannual variability of the annual average lifetime maximum intensity (LMI) for all TCs and landfalling TCs decreased slightly during the satellite era (the years since 1980). The TC annual average latitude of LMI in the satellite era exhibits a poleward migration; however, for landfalling TCs it is equatorward.

In El Niño years, TCs frequently recurve or decay before reaching the Philippine region, producing below normal numbers and landfalls in LAS and MAS. In La Niña years, TC numbers and landfalls are below normal in January-March and July-September, but above normal in April-June and October-December. A quiescent (TC-free) period occurs between LAS and MAS, ranging from 2 days-5 months (median 1.2 months) for LAS/MAS transitions, and 6 days-7 months (median 2.85 months) for MAS/LAS transitions. Wavelet analysis shows El Niño Southern Oscillation (ENSO) as the dominant mode affecting Philippine TCs, consistent with other studies. The wavelet analysis also indicates possible decadal and multi-decadal modes. 
59 providing early risk assessment, and mitigating impacts through timely preparation and 60 management. 
61 KEY WORDS: tropical cyclones, tropical cyclone metrics, Philippines, climatology, western 62 North Pacific Ocean, El Niño Southern Oscillation 


\section{Introduction}

The Philippine region lies in the tropical cyclone (TC) belt of the southwestern sector of the western North Pacific (WNP) Ocean, the most active of the world's TC basins (McBride, 1995). About 26 TCs form annually over the WNP (Ritchie and Holland, 1999), and the threat of TCs in the WNP possibly is increasing (Park et al., 2014). Over the 67-year period 1945-2011, about $70 \%$ (18) of these WNP TCs passed near or crossed the Philippines. The Philippines is located close to where most WNP TCs reach their maximum intensity (Gray, 1968; Xue and Neumann, 1984). TCs are the Philippines' worst natural hazard, in terms of human casualties, socioeconomic consequences, and also cause extensive damage to vegetation (e.g., Marler and Ferreras, 2014; 2015). Destructive winds, storm surges, landslides and extensive flooding are TC impacts affecting the Philippines. For example, in November 1991, Tropical Storm Thelma demonstrated that TCs even below typhoon intensity are devastating, causing over 5,000 deaths. Figure 1a shows tropical storm Thelma, before landfall, on November 4, 1991. Figure 1b shows Thelma's track, which produced massive flooding over mountainous central sections of the Philippines, in areas largely deforested for agriculture. In 2013, Typhoon Haiyan became the strongest and deadliest landfalling typhoon in the Philippines, with over 6,000 deaths and more than 4 million made homeless. Typhoon Haiyan is the strongest TC in recorded history to make landfall anywhere on the globe. More recently, slow-moving Typhoon Koppu (Lando) made landfall on Luzon, on October 18, 2015, bringing with it local rainfall totals exceeding a meter.

Hence, there is a clear need for a more complete understanding of Philippine TC activity, and its variability, than is currently available. The aim of this study is to develop a comprehensive climatology that extends the existing studies of Philippines TCs (e.g., Brand and Blelloch, 1973; Shoemaker, 1991; Chan, 2000; Wu et al., 2004; Chan and Xu, 2009; Kubota and 
Chan, 2009; Lyon and Camargo, 2008; Zhang et al., 2012; David et al., 2013; CorporalLodangco et al., 2016; Corporal-Lodangco and Leslie, 2016; Cinco et al., 2016). Except for the earlier and more recent work, the available studies mostly consider the Philippines in the larger context of the WNP, rather than focusing solely on individual Pacific islands and island clusters (e.g., Marler 2014, 2015), very notably those islands forming the Philippines. The present climatology is intended to provide increased social and economic planning, particularly before each more active season (MAS), defined here as June 1 to December 31. It also can assist in timely risk assessment and mitigation of TC impacts.

Chan (2000) examined WNP TC activity, to assess variations occurring prior to, during and after El Niño Southern Oscillation (ENSO) phases. His results suggest that Philippine region TC activity is above normal prior to an El Niño year, and below normal in October and November of an El Niño year. Furthermore, one year after an El Niño event, TC activity in the Philippines is below normal. Chan (2000) also found that Philippine TC activity is above normal in the year preceding a La Niña year, in September and October of La Niña years, and in the year after a La Niña event. Importantly, Chan (2000) suggested that El Niño and La Niña effects are most likely not the only factors determining WNP TC activity. The study of Corporal-Lodangco et al. (2016) focused on the interseasonal and interannual variability of Philippine TC activity associated with the various ENSO phases, and emphasized that for various reasons, such as geographical location, the characteristics of Philippine TCs are somewhat different from those of other WNP regions. To better understand the behavior of the Philippine TCs, a cluster analysis algorithm was applied to the genesis locations, tracks, and decay locations (Corporal-Lodangco and Leslie, 2016). These three characteristics of TC all affect the Philippine TC activity. The analysis identified the distinctive properties of each cluster. That study, especially the monthly 
analyses therein, revealed dominant clusters and showed clearly different behavior between the clusters.

The Philippine region is one of four areas assessed by Wu et al. (2004) for ENSO impacts on landfalling WNP TCs. Relative to Neutral years, in the September- November quarter during El Niño years, fewer TCs make landfall in the Philippines, unlike the SeptemberNovember quarter of La Niña years when more TCs make landfall. They attributed reduced Philippine region TC landfalls in El Niño years to the eastward shift in mean TC genesis locations, along with a weaker subtropical ridge, whereas they associated increased landfalls in La Niña years with a westward shift in mean genesis position and a stronger subtropical ridge. The tendency for stronger and longer-lived TCs in El Nino years over the entire WNP also has been documented in several studies (e.g. Wang and Chan, 2002; Clark and Chu, 2002 and Camargo and Sobel, 2005). Chan and Xu (2009) divided East Asia into sub-regions to examine variations in annual numbers of landfalling WNP TCs. The Philippines was included as part of the south region. They found that landfalling TC frequencies in the south TC region have large interannual (2-8 years), interdecadal (8-16 years) and even multidecadal (16-32 years) variations, with the interannual oscillation being dominant.

Kubota and Chan (2009) defined Philippine TC landfall as having occurred when a TC passed through any part of the Philippine region. They identified that interdecadal variability in Philippine TC activity related to ENSO phases and the Pacific Decadal Oscillation (PDO), and showed that low PDO phases decrease Philippine TC frequencies during El Niño years but increase TC frequencies in La Niña years. However, the effect of high PDO phases on Philippine TCs becomes indeterminate in different ENSO phases. Kubota and Chan (2009) also noted that ENSO effects on Philippine TCs occur on both intra-annual and interannual time scales. Zhang 
et al. (2012) examined June-October landfalling TCs in East Asia, during central Pacific (CP) El Niño phases, comparing them with landfalling frequencies during eastern Pacific (EP) El Niño and La Niña phases. They found that Philippine TC landfall numbers decrease in June-October of CP and EP El Niño years, but increase during EP La Niña years.

\section{Data and methods}

The Philippine TC region is defined here as being located between latitudes $5^{\circ} \mathrm{N}$ to $25^{\circ} \mathrm{N}$ and longitudes $115^{\circ} \mathrm{E}$ to $135^{\circ} \mathrm{E}$, shown in Figure 2 (black inset), adapted from Corporal-Lodangco et al. (2016). The red line in Figure 2 defines the official domain of the Philippine Atmospheric, Geophysical and Astronomical Services Administration (PAGASA) for TC responsibility, and the Philippine region used in this study is chosen to be very similar to that of PAGASA.

\subsection{Data source}

There are several TC centers with data applicable to this study: the PAGASA, the Japan Meteorological Agency (JMA), and the Joint Typhoon Warning Center (JTWC). TC records from PAGASA, JMA and JTWC were analyzed and compared, to select the most appropriate TC data archive for this study. The JTWC data, known as the "best track", includes mean sea level pressure (MSLP) that provides an important advantage over the PAGASA data, and the TC data extend back to 1945, providing the most comprehensive coverage. Chan (2008) also stated that JTWC best track dataset likely gives a better estimate of the number of intense TCs in the WNP. Moreover, from 1951 to 1980 , JMA did not include the actual values of maximum sustained winds, instead only the intensity classifications were recorded. JMA based the measurement of maximum sustained winds on wind speeds at 10 meters height sampled for 10 minutes and then 
153 averaged. JMA began recording the maximum sustained winds in 1981, but only winds of at 154 least 35 knots were included; lighter winds were set to zero knots.

All 1199 TCs that were recorded by JTWC in the Philippine domain for 1945-2011 are

156 included in this study, and the Philippine TC metrics were calculated from the JTWC best track

157 data (http://www.usno.navy.mil/NOOC/nmfc-ph/RSS/jtwc/best_tracks/). Best track data for TCs,

158 at 6-hour intervals, includes: latitude-longitude position, maximum sustained surface wind speed,

159 and minimum central pressure. TCs were counted if any parts of their tracks were within the

160 Philippines TC domain. The TC frequency is the monthly number of TCs that developed or 161 moved into the Philippine domain, and the mean and median provide the climatology. Genesis 162 locations and tracks of TCs also are from JTWC.

\section{2.2. SST and ENSO index data}

164 The Oceanic Niño Index was obtained from the National Oceanic and Atmospheric 165 Administration Climate Prediction Center (NOAA CPC, http://www.cpc.ncep.noaa.gov/). The 166 Oceanic Niño Index is the 3-month running mean of extended reconstructed sea surface 167 temperature (ERSST) Niño $3.4\left(5^{\circ} \mathrm{N}-5^{\circ} \mathrm{S} ; 120^{\circ}-170^{\circ} \mathrm{W}\right)$ anomalies, relative to the $1981-2010$ 168 Philippines TC climatology. The World Meteorological Organization (WMO) definitions of El 169 Niño and La Niña conditions were adopted in this study. For El Niño, a three-month running 170 mean of departures from normal SSTs in the Niño 3.4 region is $\geq+0.5^{\circ} \mathrm{C}$. Similarly, La Niña is 171 defined as any three-month running mean of departures from normal SSTs in Niño 3.4 region of $172 \leq-0.5^{\circ} \mathrm{C}$. A Neutral phase is defined in this study as when the departures from normal SSTs in 173 the Niño 3.4 region fall within the range of $<+0.5^{\circ} \mathrm{C}$ to $>-0.5^{\circ} \mathrm{C}$. 
174

175

176

177

178

179

180

181

182

183

184

185

186

187

188

189

190

191

192

193

194

195

\subsection{Data Analysis Methods}

Tropical cyclone activity in a TC region typically is expressed as a set of mean TC measures of frequencies, landfalls, intensities, TC days, earliest and latest season start/end dates, season lengths, genesis locations and tracks, similar to those examined by Ramsay et al. (2008) and Goebbert and Leslie (2010). A distinctive aspect of this study is the partitioning of TC activity in the Philippines initially into two seasons: a less active season (LAS) and a more active season (MAS), based on the mean monthly TC counts. The LAS, runs from January 1 to May 31, has less than one TC on average per month whereas all monthly MAS TC averages are above one (Fig. 3). The MAS which is defined in this study to span the period from June 1 to December 31. Aside from different TC statistics between these two seasons, there are different thermodynamic and dynamic environmental conditions. A unique aspect is the nature of the transition periods found between the LAS and the MAS. Statistical measures, such as medians, means, interquartile range (IQR) and linear trends were used to define TC activity. Statistics were compiled for 3, 5, 7, and 12-monthly periods, corresponding to the individual quarters, LAS, MAS and the calendar year, respectively. The time series generating these statistics are the monthly TCs counts. Three-year and five-year running means smoothed year-to-year variability.

\subsection{Quarterly periods}

TC activity in the Philippines cannot be fully demonstrated using just the LAS and MAS classification, as variations occur in the yearly quarters. Accordingly, quarterly periods, JanuaryMarch, April-June, July-September, and October-December, also are needed to capture detailed changes in intra-annual TC variations. The TC metrics all vary distinctively when grouped by quarter years. The summer (southwest) monsoon and winter (northeast) monsoon winds 
196 influence the motion and tracks of the Philippine TCs and other systems also affect the region, 197 peaking in particular months. To investigate the ENSO impacts, quarter years were used for TCs 198 entering the Philippine domain, and also for landfalling TCs. Quarterly SST indices are used to 199 classify quarters as Neutral, El Niño or La Niña phases of ENSO. The quarterly TC time series 200 were standardized, by subtracting 1981-2010 long-term means from individual TC counts, and 201 dividing the difference by standard deviation (Corporal-Lodangco and Leslie, 2016), to provide 202 representative TC counts for different ENSO phases. The numbers of TCs during Neutral phases 203 are greater than during El Niño and La Niña phases, because the time that ENSO is in Neutral 204 periods dominates that of the El Niño and La Niña phases. This dominance would lead to false 205 claims, without standardization, about the impact of ENSO phases on Philippine TCs. Simply 206 put, the standardized TC counts indicate how many standard deviations an observation is above 207 or below the mean.

\section{Results and Discussion}

\subsection{TC Statistics}

210 TC activity is observed in every month in the Philippine region. For 1945-2011, the Philippine 211 region had 1,199 TCs, with an annual long-term mean of 17.9. Tables 1 and 2 summarize TC 212 activity in the Philippine region. The TC monthly count clearly suggests the existence of two 213 distinct seasons, the LAS and the MAS. The LAS represents the relatively quiet phase of TC 214 activity, with the monthly mean and median both less than one TC. In contrast, the MAS has all 215 monthly means greater than one. February has the lowest TC frequency, and January-March is 216 the least active TC quarter. Lander (1994) found similar TC behavior over the entire WNP 217 basin, and related it to less frequent WNP cyclogenesis. In the LAS, the mean and median for 
218 TC number are almost equal, with 2.16 and 2.0, respectively. Similarly, the mean and median 219 for TC landfall are 0.96 and 1.0, correspondingly. The monthly MAS TC median ranges from 1

220 to 3, and the MAS accounts for $\sim 89 \%$ of the mean annual numbers of TCs affecting the 221 Philippines. The MAS TC mean is 15.73 and the median is 15 . The mean for TC landfall is 5.55 222 and the median is 6.0. The peak months are July-September, with August the most active month 223 of the year (Fig. 3). Neumann (1993) indicated that the WNP peak TC season includes summer 224 and fall, encompassing the MAS.

225 The annual number of TCs ranges from a minimum of 10 in 1946 to a maximum of 28 in 2261993 (Fig. 4a). Comparing the annual number of TCs with the number of TCs during the LAS 227 and MAS, the mean annual total is dominated by TCs from the MAS. The LAS TC IQR is 2, and 228 the landfall IQR also is 2. The MAS has a TC IQR of 4.5 and the landfall IQR is 3. These LAS 229 and MAS findings are consistent with Gray (1985), confirming the global frequency of TC varies 230 on an interseasonal time scale with alternating active and inactive periods. The linear trend lines 231 for the LAS, MAS and annual TCs in Figure 4a all suggest increases in the numbers of TCs for 232 the period 1945-2011. However, when the satellite era, defined here as beginning in 1980 and 233 ending in 2011 because the dataset used in the study is only available until 2011, is considered 234 separately (Fig. 4b), it was found that there is a decreasing trend in both the MAS and the annual 235 numbers of TCs. There is no change in the trend of LAS number of TCs during the satellite era. 236 The decreasing trend in the annual numbers of TCs is consistent with the trend in WNP TCs 237 (Moon et al., 2015).

\subsection{Season start/end dates and lengths}

239 The year-to-year variation of TC activity in the Philippine region is shown in Fig. 5. The TC 240 frequency over the region varies on an interseasonal time scale, with alternating LAS, quiescent 
241 periods, and MAS. The season start date is the day during a season when the first TC is located 242 in the Philippine region. The season end date is defined as the day when the last TC is inside the 243 domain. The season start date is the value at the lowest tip of the bar, and the season end date is 244 the value at the upper tip of the bar in Fig. 5. The mean start and end dates for the LAS are 245 March 6 and May 5, respectively, whereas for the MAS, the mean start and end dates are June 20 246 and December 10, respectively. The season length is from the first day there is a TC in the 247 Philippine region to the last day there is a TC in the region. The annual season length is the total 248 length of blue and red bars. For the entire period of 1945-2011, there is an increasing trend in 249 the LAS length whereas a decreasing trend is seen in MAS length. Typically, the LAS last TC 250 days are within the season period. However, there are years when LAS end dates occur in June, 251 which is part of the MAS. After the LAS ends, it takes a mean of 1.5 months and a median of 1.2 252 months before the MAS commences. The gap between the LAS and MAS is as brief as 2 days 253 and as long as $\sim 5$ months. The gap between the two seasons is referred to here as the 254 "quiescent" period that, as far as the authors are aware, has never previously been mentioned. 255 The quiescent periods confirm the distinct division of the year into two seasons, the LAS and the 256 MAS. After the MAS, the quiescent period again is observed and is much longer than the 257 quiescent period occurring after the LAS. It ranges from 6 days to just over 7 months (Table 1), 258 with a mean and a median of $\sim 3$ months.

Figures 6-7 describe the characteristics of LAS and MAS in detail. A 5-year running 260 mean is applied to all analyses to smooth the short-term fluctuations and highlights the long-term 261 trend. The yearly LAS length, as shown in Figure 6a, is the length of the blue bars and varies 262 widely from zero days, in years when no TCs affect the Philippines, to 155 days in 1953. The 263 LAS length is much shorter than the MAS with a mean length of 52 days. The LAS median 
264 length is 38 days. The $25^{\text {th }}$ and $75^{\text {th }}$ percentiles of the LAS length are 3.5 and 95.5 days, 265 respectively, and the IQR is 92 days. There are 11 LAS years with no TCs. The LAS TCs begin 266 to form in or enter the Philippine domain as early as January $2^{\text {nd }}$ and as late as May $31^{\text {st }}$. The 267 mean LAS start date is March $4^{\text {th }}$ and the median is February $28^{\text {th }}$. However, the LAS ends as 268 early as January $11^{\text {th }}$ and as late as June $6^{\text {th }}$. The mean LAS end date is May $6^{\text {th }}$ and the median 269 end date is May $20^{\text {th }}$. Interannual variability is very high in the LAS length time series. The 270 LAS length has two maxima in 1955 and 1987 and a minimum in 1972 (Fig. 6b). The earliest 271 LAS start date from the 5-year running mean occurs in 1986, and the latest is in 1979 (Fig. 6c). 272 The earliest LAS end date is in 1972 and the latest is in 1997 (Fig. 6d). The trend lines for the 273 LAS length and the 5-yr running mean of LAS length both show an increasing trend during the 274 period 1945-2011, and the season start and end dates becoming later (Fig. 6a-d). When only the 275 satellite era is considered for LAS lengths (Figs. 6e, f), the trend reverses because the season 276 start dates are later as seen in the substantially sharper trend slope (Fig. 6g). The trend line for 277 the season end dates indicates an almost flat trend (Fig. 6h).

278 For the MAS (Fig. 7a), the earliest start date is June $1^{\text {st }}$ and the latest is July $30^{\text {th }}$, with 279 June $20^{\text {th }}$ and June $18^{\text {th }}$ as the mean and median start dates, respectively. The MAS ends as early 280 as September $10^{\text {th }}$ and as late as January $5^{\text {th }}$ the following year, with a mean (median) MAS end 281 date of December 10 (December 16th). The mean MAS length is 174 days and the median is 282176 days, with no TC-free years. The MAS length has a minimum of 96 days in 2002 and a 283 maximum of 209 days in 1950. The $25^{\text {th }}, 50^{\text {th }}$ and $75^{\text {th }}$ percentiles of MAS length are $161.5,176$, 284 and 189.5 days, respectively. The IQR MAS length is 28 days. The 5-year running mean of the 285 MAS length is shown in Fig. 7b. The longest MAS lengths are in 1950 and 1987, and the 286 minima occur in 1955, 1971 and 2000. Similarly, the maxima in the 5-year running means of 
start dates (Fig. 7c) and end dates (Fig. 7d) indicate the latest start/end dates, whereas the minima indicate the earliest start/end dates. Unlike the LAS, which has an irregular annual season length, the MAS length varies less (Fig. 7a), consistent with the IQR (Table 1). Both 1945-2011 and 1980-2011 periods indicate a decreasing trend in MAS lengths (Figs. 7a,b and 7e,f). The MAS start dates in 1945-2011 period shows a flat trend (Fig. 7c). However, the trend in MAS start dates in satellite era appears to be increasing, which means the season start dates are becoming later or a later onset of the MAS (Fig. 7g). For 1945-2011 period, the trend line in the MAS end dates indicates a slight decreasing trend, which means the MAS ends a little earlier (Fig. 7d). However, in the 1980-2011 period, the trend line suggests a more rapid decrease, which means the season end dates are becoming much earlier (Fig. 7h). The slopes of the trend lines in MAS length and start/end dates are considerably sharper during the satellite era.

\subsection{TC days}

A TC day has at least one TC in the Philippine domain. A TC day can vary from an hour up to 24 hours. The number of LAS TC days ranges from 0 to 25 days (Fig. 8a). The LAS mean TC days is 9 and the median is 8 . The $25^{\text {th }}$ and $75^{\text {th }}$ percentiles of LAS TC days are 2.5 and 13.5 days, respectively, with an IQR of 11 days. The number of MAS TC days far exceeds LAS TC days. The MAS TC days range from 22 to 102 (Fig. 8b). The MAS mean TC days is 55 and the median is 51 . The $25^{\text {th }}$ and $75^{\text {th }}$ percentiles of MAS TC days are 44 and 64 days, respectively, and an IQR of 20 days. The annual TC days count is the sum of LAS and MAS TC days (Fig. 8c). The annual TC days range from $23-114$, the mean TC days is 64 , and the median is 61 days. The $25^{\text {th }}$ and $75^{\text {th }}$ percentiles of annual TC days are 50 and 76 days, with an IQR of 26 days. 
309 TC landfall is defined in this study as occurring when the TC circulation center reaches the 310 Philippine coastline. The Philippine archipelago occupies just 6\% of the WNP and, of 1199 TCs 311 that occurred during the study period, many (435, or 36\%) struck the Philippines and more came 312 close to making landfall. The annual long-term mean of TC landfalls in the Philippine domain is 313 6.5, with a median of 7.0. Quarterly statistics for TC counts and landfalls are in Table 2. July314 September has more TC activity, with $48.8 \%$ of the TC count. In July-September, the 315 environmental elements necessary for TC genesis are more likely to be present. October316 December has the largest percentage of quarterly landfalling TCs, with $53 \%$ of October317 December TCs, and 45\% of total TC landfalls. Although July-September has the highest mean 318 TC occurrence in the Philippine domain, the October-December season has the greatest mean 319 number of landfalling TCs, attributable to the weak monsoon westerlies, strong trade wind 320 easterlies and an intense subtropical anticyclone north of the Philippines, producing more TCs 321 with straight line tracks and thereby increasing the likelihood of TCs making landfall in the 322 Philippines. TCs are more intense when straight-moving TCs remain at lower latitude. There are 323 more recurving TCs in July-September, coinciding with the peak of summer (southwest) 324 monsoon, weak trade wind easterlies, a deep monsoon trough and a subtropical anticyclone well 325 northeast of the Philippines, causing the TC tracks to recurve and thereby reducing landfalling 326 TCs compared with the mean number of October-December landfalls. The conditions conducive 327 for straight-moving and recurving TCs are cited in the work of Chen et al. (2009). 
329 The TC intensity categories used in this study are based on observed maximum sustained winds near the center, at 6-hourly intervals. Here, Philippine TC activity comprises three TC 331 categories, namely, tropical depression (TD), tropical storm (TS) and typhoon (TY). A TD has maximum sustained winds from $9.73 \mathrm{~m} \mathrm{~s}^{-1}$ to $17.9 \mathrm{~m} \mathrm{~s}^{-1}$, a TS has sustained winds from $18.0 \mathrm{~m} \mathrm{~s}^{-}$ ${ }^{1}$ to $32.78 \mathrm{~m} \mathrm{~s}^{-1}$, and a TY has sustained winds exceeding $32.78 \mathrm{~m} \mathrm{~s}^{-1}$. Figure 9a shows quarterly TC frequency for the three intensity categories. Of these, TDs are least likely in each quarter, with $\sim 16 \%$ of the total TCs. The 345 TSs during $1945-2011$, were $\sim 29 \%$ of all TCs, and were the second most frequent TC intensity category in each quarter. About 55\% of Philippines TCs are TYs with an annual average of 10, a high percentage compared with other TC basins (e.g. NOAA Hurricane Research Division 2014). July-September has the highest frequency of TYs but, in October-December, TYs are most likely to occur, with $\sim 59 \%$ of October-December TCs reaching TY intensity. Figure 9b shows quarterly landfall intensities. Of 435 total TC landfalls,

$341103(24 \%)$ are TDs, $132(30 \%)$ are TSs and $201(46 \%)$ are TYs. Most ( 36\%) of January-March TCs are TDs. The majority of the April-June, July-September and October-December TCs are 343 TYs. October-December has the highest frequency of landfalling TCs and mostly of TY 344 intensity. shows the annual average lifetime maximum intensity (LMI; Kossin et al., 2014) of all TCs (Fig. 10a) and the annual average LMI of landfalling TCs (Fig. 10b). Both all TCs and landfalling

348 TCs annual average LMI imply a slight decreasing trend during the satellite era. The results 349 suggest a weakening trend in the maximum sustained winds of Philippine TCs. This observation 350 is not consistent with most climate change predictions of an increase in the frequency of intense 
351 TCs in a warming world scenario. However, Chan (2009) found that not all TC basins respond 352 uniformly under climate change. Hence, further research in the future is needed to resolve such 353 conflicting results.

$354 \quad 3.6$ Variability

355 Interannual and interdecadal variations in the frequency of Philippine TCs and landfalling TCs 356 for 1945-2011 are shown in Fig. 11. Since 1945, large amplitude variations are apparent in the 357 time series of the annual number of TCs. In Fig. 11a, the green line is the long-term mean of 358 TCs in the Philippine domain whereas, the pink line is the 3 -year running mean, and the orange 359 line is the long-term linear trend line. The 3-yr running mean preserves short-term fluctuations, 360 such as the interannual variability. Years with 3-year running means below the long-term mean 361 of 17.9 are in the below mean period (BMP), and all years with above mean TCs are in the above 362 mean period (AMP). The BMP (yellow areas) ranges from 1 to 10 years, whereas the AMP 363 (blue areas) ranges from 1 to 15 years. Significant variations from the mean occur in the time 364 series, including long-term cycles in 1954-1963 and 1982-1996 periods for BMP and AMP, 365 respectively. Short-term cycles (1945-1951, 1954-1963, 1966-1970, 1973, 1976-1977, 1981, 366 1997-1998, 2001-2002, 2006-2007, and 2009-2011 for BMP; 1952-1953, 1964-1965, 1971367 1972, 1974-1975, 1978-1980, 1982-1996, 1999-2000, 2003-2005, and 2008 for AMP) also are 368 evident in the 3 -year TC count running means. Figure $11 \mathrm{~b}$ is similar, but for annual landfalls in 369 the Philippine domain, and the long-term mean is 6.5 (green line). The landfall time series also 370 shows year-to-year variability. The AMP ranges from 1 to 10 years and the BMP from 2 to 15 371 years. The Philippines is influenced by environmental factors identified by Chan (2005), who 372 attributed interannual variability in WNP TC activity to changes in planetary-scale flow patterns. 373 SST changes in the central and eastern equatorial Pacific are associated with ENSO. TC 
374 variability also is related to the quasi-biennial oscillations phases due to its modification of the

375 vertical wind shear. Interdecadal variability in annual TC and landfalling TC counts are related 376 to PDO but also to the location, strength and size of the North Pacific subtropical high. The trend 377 lines for all TCs and landfalling TCs during the 1945-2011 period both indicate increasing trend. 378 When only the satellite era is considered, the trend in the numbers of all TCs reverses (Fig. 12a) 379 which is consistent with the trend in the frequency of WNP TCs (Moon et al., 2015). Figure 12b 380 also shows decreasing trend in the number of landfalling TCs.

381 The interannual variability and trends of the annual average latitude of annual average 382 LMI for all TCs and landfalling TCs during the satellite era have also been investigated. Figure 383 13a shows the annual average latitude of the annual average LMI for all TCs where the trend line 384 implies a poleward migration of LMI annual average latitude, consistent with the observed 385 poleward shift of intense storms in WNP (Kossin et al., 2014 and Moon et al., 2015). But when 386 the interannual variability of landfalling TCs is examined, the trend reverses. There is a slight 387 negative trend, which suggests that the annual average latitude of LMI of landfalling TCs is 388 slightly going equatorward (Fig. 13b).

\subsection{Genesis and tracks}

390 Over $80 \%$ of TCs in the WNP form between the Equator and within $20^{\circ} \mathrm{N}$ (Frank and Roundy, 391 2006). Briegel and Frank (1997) used the studies of Gray (1968, 1979, 1985) to define the 392 climatological conditions necessary for tropical cyclogenesis. These include sea surface 393 temperatures above $\sim 26.5^{\circ}-27.0^{\circ} \mathrm{C}$ coupled with a relatively deep oceanic mixed layer, cyclonic 394 low-level relative vorticity and planetary vorticity, weak (preferably easterly) vertical wind 395 shear, and organized deep convection in an area of large-scale ascending motion and high 
midlevel humidity. In the Philippine region, these necessary conditions are satisfied all year, especially in the MAS, so TCs can form in all months.

Philippine TC genesis locations and tracks exhibit regular monthly spatial progression. Genesis locations are the latitude-longitude positions where a TC is initially recorded by JTWC, even if it is outside the defined domain at the time of genesis. Depending on time of the year, genesis locations range widely from $2.5^{\circ} \mathrm{N}$ to $27.5^{\circ} \mathrm{N}$, as far west as $107^{\circ} \mathrm{E}$, and eastward to $179.5^{\circ} \mathrm{E}$. In January-March, TC genesis locations are confined from $3^{\circ} \mathrm{N}$ to $16^{\circ} \mathrm{N}$, and from $123^{\circ} \mathrm{E}$ to $179.5^{\circ} \mathrm{E}$ (Fig. $14 \mathrm{a}$ ), and no TCs develop in the western side of the Philippines or in the South China Sea. Both large-scale and synoptic-scale circulations influence track type (Harr and Elsberry, 1991). Most ( 76\%) tracks are straight moving, although some recurve (24\%, Fig. 14e). Like genesis locations, TC tracks are confined to lower latitudes, making landfall at $<23^{\circ}$ N. Some TC tracks reach the South China Sea. April-June is marked by an increase $(\sim 250 \%)$ in the genesis numbers illustrated in Fig. $14 \mathrm{~b}$ as denser genesis points. Genesis locations extend farther north to $22^{\circ} \mathrm{N}$, about $6^{\circ}$ latitude higher than January-March genesis locations but the southern boundary does not change. Their longitudinal extent is $<166^{\circ} \mathrm{E}$ and some TCs form in the South China Sea, reaching as far west as $109^{\circ} \mathrm{E}$. As the genesis locations move north, the tracks extend up to $46^{\circ} \mathrm{N}$ (Fig. 14f). TC formation increases rapidly in JulySeptember (a 213\% increase over April-June), the quarter with the highest frequency of TC genesis (Fig. 14c). The latitudinal and longitudinal extent of TC genesis also is greatest in JulySeptember with the genesis locations extending farthest north, to $27^{\circ} \mathrm{N}$, about $5^{\circ}$ latitude beyond April-June, and its longitudinal extent is from $111^{\circ} \mathrm{E}$ to $177^{\circ} \mathrm{E}, 11^{\circ}$ longitude farther eastward than April-June. Again, the southern limit of the genesis locations is similar. July-September TC tracks extend farther northeast, beyond $55^{\circ} \mathrm{N}$ (Fig. 14g). TC tracks also reach main land China. 
419 The October-December quarter has reduced TC genesis relative to July-September (Fig. 14d).

$420 \mathrm{TC}$ genesis locations in October-December reach almost to $25^{\circ} \mathrm{N}$ and extend from $107^{\circ} \mathrm{E}$ to

$421178^{\circ} \mathrm{E}$. TCs in October-December have both recurving and straight-moving tracks and reach

$42253^{\circ} \mathrm{N}$ (Fig. 14h). Quarterly genesis locations of Philippine landfalling TCs are in Figs. 14i-141.

423 About $36 \%$ of Philippine region TCs make landfall, with fewer genesis points compared with

424 Figs. 14a-14d. Landfalling TCs, depending on the quarter season, have a mean westward to 425 west-north-westward direction, but straight moving landfalling TCs especially those in lower 426 latitudes originating from South China Sea can move eastward (Figs. 14m-14p). Genesis 427 locations of landfalling TCs have narrower latitudinal and longitudinal bounds, closer to the 428 Philippines, particularly in July-September.

\section{3.8. The role of ENSO}

430 WNP TC activity has interannual variability (Landsea 2000), linked to ENSO (e.g., Chan 1985, 431 Dong 1988, Lander 1993, 1994) and is attributed to the longitudinal shift of the Walker 432 circulation (Chan 1985, Wu and Lau, 1992). This is not necessarily the case for the entire WNP.

433 For example, in the South China Sea, Goh and Chan (2010) found no clear link between TC 434 frequency and El Niño and La Niña phases. Gray (1968) suggested that monthly and seasonal 435 variations in TC activity are related to large-scale deviations from climatology. The Philippines, 436 situated in the WNP, is strongly affected by ENSO. A wavelet analysis performed in this study 437 confirms that ENSO is the major global mode influencing Philippine TC activity (Fig. 15a). The 438 most significant mode is the approximately 2-7 year ENSO signal, as shown in the global 439 wavelet spectrum (Fig. 15b). There is a suggestion that ENSO is more active every 20 years, in 440 the 1950s, 1970s, and 1990s. There are 2 other peaks in the global power spectrum, at 441 approximately 10 and 30 years, corresponding to decadal and multidecadal periods. However, 
442 they are not significant at the $95 \%$ confidence level, likely due to the limited length of the time

443 series. Notably, Kubota and Chan (2009) found decadal and multidecadal signals in their

444 wavelet analysis of a much longer Philippine TC time series, from 1902-2005.

445 The seasonal variability of the Philippine TC activity during Neutral, El Niño and La

446 Niña phases of ENSO is shown in Fig. 16, adopted from Corporal-Lodangco et al. (2016). The

447 green, red and blue bars represent Neutral, El Niño and La Niña phases, respectively. The

448 standardized quarterly TC counts during each ENSO phase are in Fig. 16a. Remarkably,

449 Philippine TC activity during the Neutral phase, relative to El Niño and La Niña phases, is

450 always above normal from January-March to October-December. Below normal TC activity

451 occurs all year during El Niño phases. Consistent with Chan (2000), in La Niña events, April-

452 June and October-December have above normal TC activity unlike the below normal TC activity

453 in January-March and July-September. Philippine TC landfall numbers were examined for

454 different ENSO phases (Fig. 16b). TC landfalls in Neutral phases are above normal in all

455 quarters. Although below normal landfalling TCs occurs all year during El Niño phases, there is

456 a notable marginally negative TC landfalls in July-September. The sharp drop in TC landfalls

457 during October-December, in El Niño episodes, supports the findings of Wu et al. (2004).

458 January-March and July-September have below average La Niña phase TC landfalls, contrasting

459 with above normal landfalls in La Niña April-June and October-December quarters. High TC

460 landfall counts in October-December also match the results of Wu et al. (2004). Chan (1985,

461 2000) and Wang and Chan (2002) emphasized large-scale climate factors, such as ENSO, in

462 determining genesis and preferred TC tracks, due to monsoon trough displacement, and changes

463 in vertical wind shear near the dateline (Lander 1994, 1996; Clark and Chu, 2002) on landfalling 
464 TCs. They also suggest that ENSO impacts on WNP TCs depend on the strength of ENSO 465 phases. For example, suppression of landfalls is greater in strong El Niño years.

466

467

468

469

\section{Conclusions}

A detailed climatology was generated of the Philippine TC region, which has the highest annual median number of TCs (17) of any TC sub-basin on the globe. Two distinct Philippine TC seasons, the LAS (January 1- May 31) and MAS (June 1-December 31) are readily identified. The LAS and MAS seasons differ notably in a number of key TC metrics, such as TC frequency and landfall counts, season length, TC days, TC genesis locations, and tracks. Large amplitude variations are present in annual TC numbers, with the LAS being relatively inactive, and February is the least active month of the entire calendar year. In the Philippine domain, JanuaryMarch has the lowest quarterly TC frequency, and TCs in February and March generally also are weaker. More TCs affect the Philippine region during the MAS because the environmental conditions favor TC development. July-September is the most active quarter and August is the most active month in the Philippine domain; both are periods when TC activity in the entire WNP is greatest. Observed LAS, MAS, and the quiescent periods separating the LAS and MAS, result from interseasonal large-scale circulation variability driving changes in TC activity.

Through the year, TC genesis locations and tracks move northward, reaching their highest latitudes during July-September, then regress in October-December. Straight-moving TCs are confined to lower latitudes, whereas recurving TCs occupy relatively higher latitudes and follow a northeast direction after recurving. The most common track is straight-line, and is observed year-round. Over $60 \%$ of TCs have long, straight track originating farther east from the Philippine region. Thus they have longer duration times over warm tropical SSTs and, because 
486 of climatologically low vertical wind shear, are more likely to become TYs than TCs that recurve 487 northeastward.

488 This study showed that ENSO is the dominant global mode influencing Philippine TC 489 activity, confirmed by a wavelet analysis. Philippine TC activity is above normal in Neutral 490 phases. The impact of El Niño events on Philippine TCs is to reduce the number of TCs year491 round, whereas La Niña events support above normal TC activity in April-June and October492 December, and below normal activity in January-March and July-September. The difference in 493 TC genesis locations during El Niño and La Niña phases affects the numbers of TCs entering the 494 Philippine domain. The eastward displacement of cyclogenesis during El Niño phases typically 495 causes TCs to recurve or dissipate before entering the Philippines, with fewer TCs entering the 496 region. The frequency of TC landfalls in the Philippine domain also varies with ENSO phases. 497 Above normal TC landfalls occur in Neutral phases. In El Niño years, TC landfalls are below 498 normal, although only marginally in July-September. The January-March and July-September 499 quarters of La Niña phases have below normal TC landfalls but above normal in April-June and 500 October-December. The above normal numbers of TCs and landfalling TCs in April-June and 501 October-December is attributed to the significant westward shift in mean genesis position of the 502 Philippine TCs during La Niña phases (Corporal-Lodangco et al., 2016), and the presence of a 503 strong subtropical ridge generating a steering flow toward the west northwest. Other dynamics in 504 WNP are responsible for the variability of Philippine region TC activity. For example, TCs 505 preferentially occur in convective phases of the Madden-Julian Oscillation (e.g., Liebmann et al., 506 1994).

Finally, further analysis is required to explain the quiescent periods identified between 508 the LAS and MAS and conversely. This phenomenon will be investigated as part of continued 
509 research on Philippine TCs, specifically attempting to identify the possible reasons for the 510 existence of the quiescent period, and examining the heaviest rainfall events resulting from 511 Philippine TCs as part of an extreme events study.

\section{Acknowledgments}

513 This research was supported by the NOAA Cooperative Institute for Mesoscale Meteorological 514 Studies (CIMMS), University of Oklahoma, Norman, Oklahoma, USA. The authors thank Dr. 515 Michael B. Richman, School of Meteorology, University of Oklahoma, for his helpful statistical 516 advice. 


\section{References}

518 Brand S, Blelloch JW. 1973. Changes in the characteristics of typhoons crossing the Philippines. J. Appl. Meteor. 12: 104-109.

Briegel LM, Frank WM. 1997. Large-scale influences on tropical cyclogenesis in the western

Camargo SJ, Sobel AH. 2005. Western North Pacific tropical cyclone intensity and ENSO. J. Climate 18:2996-3006.

Chan JCL. 1985. Tropical cyclone activity in the Northwest Pacific in relation to the El

Chan JCL, Xu M. 2009. Interannual and interdecadal variations of landfalling tropical cyclones

Chan JCL. 2009. Thermodynamic control on the climate of intense tropical cyclones. Proc. $R$. Soc. 465: 3011-3021. in East Asia. Part I: time series analysis. Int. J. Climatol. 29: 1285-1293.

Chen TC, Wang SY, Yen MC, Clark AJ. 2009. Impact of the intraseasonal variability of the 
western North Pacific large-scale circulation on tropical cyclone tracks. Wea. Forecasting 24: $646-666$.

Cinco TA, de Guzman RG, Ortiz AMD, Delfino RJP, Lasco RD, Hilario FD, Juanillo EL, Barba R, Ares ED. 2016. Observed trends and impacts on tropical cyclones in the Philippines. Int. J. Climatol. doi:10.1002/joc.4659.

Clark JD, Chu PS. 2002. Interannual variation of tropical cyclone activity over the Central North Pacific. J. Meteor. Soc. of Japan 80: 403-418.

Corporal-Lodangco IL, Leslie LM, Lamb PJ. 2016. Impacts of ENSO on Philippine tropical cyclone activity. J. Climate 29: 1877-1897.

Corporal-Lodangco IL, Leslie LM. 2016. Cluster Analysis of Philippine Tropical Cyclone Climatology: Applications to Forecasting. Journal of Climatology \& Weather Forecasting 4: 152. doi:10.4172/2332-2594.1000152.

David CPC, Racoma BAB, Gonzales J, Clutario MV. 2013. A manifestation of climate change? A look at Typhoon Yolanda in relation to the historical tropical cyclone archive. Sci. Diliman 25(2).

Dong K. 1988. El Niño and tropical cyclone frequency in the Australian region and the northwest Pacific. Australian Meteor. Magazine 36: 219-25.

Frank WM, Roundy PE. 2006. The role of tropical waves in tropical cyclogenesis. Mon. Wea. Rev. 134: 2397-2417. 
556 Goebbert KH, Leslie LM. 2010. Interannual variability of northwest Australian tropical 557 cyclones. J. Climate 23: 4538-4555.

558 Goh, AZ, Chan JCL. 2010. Interannual and interdecadal variations of tropical cyclone activity in 559 the South China Sea. Int. J. Climatol. 30: 827-843.

560 Gray WM. 1968. Global view of the origin of tropical disturbance and storms. Mon. Wea. Rev. 561 96: 669-700.

Kossin JP, Emmanuel KA, Vecchi GA. 2014. The poleward migration of the location of tropical

Gray WM. 1985. Tropical cyclones global climatology. Volume 1, WMO/TD-No. 7f2, World Meteorological Organization. 3-19.

Harr PA, Elsberry RL. 1991. Tropical cyclone track characteristics as a function of large-scale circulation anomalies. Mon. Wea. Rev. 119: 1448-1468.

Lander MA. 1993. Comments on "A GCM simulation of the relationship between tropical storm formation and ENSO.” Mon. Wea. Rev. 121: 2137-2143. 
575 Lander MA. 1994. An exploratory analysis of the relationship between tropical storm formation 576 in the western North Pacific and ENSO. Mon. Wea. Rev. 122: 636-651.

577 Lander MA. 1996. Specific tropical cyclone tracks and unusual tropical cyclone motions 578 associated with a reverse-oriented monsoon trough in the western North Pacific. Wea. $579 \quad$ Forecasting 11: 170-186.

580 Landsea CW. 2000. El Niño-Southern Oscillation and the seasonal predictability of tropical $581 \quad$ cyclones. In El Niño: Multiscale variability and global and regional impacts, edited by HF. 582 Díaz and V. Markgraf, 149-81. Cambridge University Press: Cambridge, UK.

583 Liebmann B, Hendon HH, Glick JD. 1994. The relationship between tropical cyclones of the 584 western Pacific and Indian Oceans and the Madden-Julian oscillation. J. Meteor. Soc. Japan 585 72: 401-411.

Lyon B, Camargo SJ. 2008. The seasonally varying influence of ENSO on rainfall and tropical

Marler TE, Ferreras U. 2014. Differential leaflet mortality may influence biogeochemical cycling following tropical cyclones. Communicative \& Integrative Biology 7, e27924

Marler TE. 2014. Pacific island tropical cyclones are more frequent and globally relevant, yet 591 less studied. Frontiers in Environmental Science 2, 42. tropical cyclone damage. J. Geography \& Natural Disasters 5: 1421-1427. 
595 Marler TE. 2015. Promoting the confluence of tropical cyclone research. Communicative \& $596 \quad$ Integrative Biology 8: e101765.

597 McBride JL. 1995. Tropical cyclone formation. Global perspective on tropical cyclones. $598 \quad W M O / T D$ No. 693: 63-105.

599 Moon I-J, Kim S-H, Klotzback P, Chan JCL. 2015. Roles of interbasin frequency changes in the 600 poleward shifts of the maximum intensity location of tropical cyclones. Environ. Res. Lett. 601

Neumann CJ. 1993. Global overview. In Global Guide to Tropical Cyclone Forecasting, edited by G. J. Holland, $W M O / T D$ No. 560: 1.1-1.56.

604 NOAA Hurricane Research Division. 2014. In Tropical Cyclone Records. Available online at 605 http://www.aoml.noaa.gov/hrd/tcfaq/E10.html (accessed on 7 August 2015).

606 Park, DR, Ho C-H, Kim J-H. 2014. Growing threat of intense tropical cyclones to East Asia over the period 1977-2010. Environ. Res. Lett. 9: 014008 (7pp). doi:10.1088/17489326/9/1/014008.

609 Ramsay HR, Leslie LM, Lamb PJ, Richman MB, Leplastrier M. 2008. Interannual variability of 610 tropical cyclones in the Australian region: Role of large-scale environment. J. Climate 21: $611 \quad 1083-1103$.

612 Ritchie EA, Holland GJ. 1999. Large-scale patterns associated with tropical cyclogenesis in the 613 western Pacific. Mon. Wea. Rev., 127: 2027-2043. 
614 Shoemaker DN, 1991. Characteristics of tropical cyclones affecting the Philippine Islands. $615 \quad$ NOCC/JTWC Technical Note 91-1, 35 pp.

616 Wang B, Chan JCL. 2002. How strong ENSO events affect tropical storm activity over the 617 western North Pacific. J. Climate 15: 1643-1658.

618 Wu MC, Chang WL, Leung WM. 2004. Impacts of El Niño-Southern Oscillation events on 619 tropical cyclone landfalling activity in the western North Pacific. J. Climate 17: 1419-1428.

$620 \mathrm{Wu}$ G, Lau N-C. 1992. A GCM simulation of the relationship between tropical storm formation 621 and ENSO. Mon. Wea. Rev. 120: 958-977.

622 Xue Z, Neumann CJ. 1984. Frequency and motion of western North Pacific tropical cyclones. 623 NOAA Tech. Memo, NWS NHC 23 (PB85106466), 89 pp.

624 Zhang W, Graf H-F, Leung Y, Herzog M. 2012. Different El Niño types and tropical cyclone 625 landfall in East Asia. J. Climate 25: 6510-6523. 
627 Table 1. The metrics of the Philippine TC activity during the two distinct seasons: less active

628 season (LAS) and more active season (MAS).

\begin{tabular}{|l|c|c|l|c|c}
\hline Tropical Cyclone Metrics & $\begin{array}{c}\text { Less Active } \\
\text { Season }\end{array}$ & $\begin{array}{c}\text { More Active } \\
\text { Season }\end{array}$ & Tropical Cyclone Metrics & $\begin{array}{c}\text { Less Active } \\
\text { Season }\end{array}$ & $\begin{array}{c}\text { More Active } \\
\text { Season }\end{array}$ \\
\hline Season TC Mean & 2.16 & 15.73 & Season Earliest Start Date & $1 / 2$ & $6 / 1$ \\
\hline Season TC Median & 2 & 15 & Season Latest Start Date & $5 / 31$ & $7 / 30$ \\
\hline Season Landfall Mean & 0.96 & 5.55 & Season Mean Start Date & $3 / 4$ & $6 / 20$ \\
\hline Season Landfall Median & 1 & 6 & Season Median Start Date & $2 / 28$ & $6 / 18$ \\
\hline Season TC Number IQR* & 2 & 4.5 & Season Earliest End Date & $1 / 11$ & $9 / 10$ \\
\hline Season Landfall IQR* & 2 & 3 & Season Latest End Date & $6 / 6$ & $1 / 5$ \\
\hline Quiescent Period Mean & 1.5 months & 2.83 months & Season Mean End Date & $5 / 6$ & $12 / 10$ \\
\hline Quiescent Period Median & 1.2 months & 2.85 months & Season Median End Date & $5 / 20$ & $12 / 16$ \\
\hline Quiescent Period Minimum & 2 days & 6 days & Season Mean Length & 52 days & 174 days \\
\hline Quiescent Period Maximum & 5 months & 7 months & Season Median Length & 38 days & 176 days \\
\hline Quiescent Period IQR* & 1.5 months & 3 months & Season Length IQR* & 92 days & 28 days \\
\hline Median TC Days & 8 days & 51 days & TC Days IQR* & 11 days & 20 days \\
\hline
\end{tabular}


630 Table 2. The statistics of Philippine tropical cyclones (TCs) and landfalls are presented in quarters.

631 ALL is the sum of 4 quarters. The bottom row is the total and percentage of all tropical cyclones 632 and landfalls for the period 1945-2011. The numbers in red are the maximum values.

\begin{tabular}{|c|c|c|c|c|}
\hline Quarter & $\begin{array}{c}\text { Number of } \\
\text { TCs }\end{array}$ & $\begin{array}{c}\text { Percentage } \\
\text { of TCs }\end{array}$ & $\begin{array}{c}\text { Number of } \\
\text { Landfalling TCs }\end{array}$ & $\begin{array}{c}\text { Percentage of } \\
\text { Landfalling TCs }\end{array}$ \\
\hline January-March & 54 & $4.5 \%$ & 25 & $46 \%$ \\
\hline April-June & 187 & $15.6 \%$ & 70 & $37 \%$ \\
\hline July-September & 585 & $48.8 \%$ & 143 & $24 \%$ \\
\hline October-December & 373 & $31.1 \%$ & 197 & $53 \%$ \\
\hline ALL & 1199 & $100 \%$ & 435 & $36 \%$ \\
\hline
\end{tabular}

633 

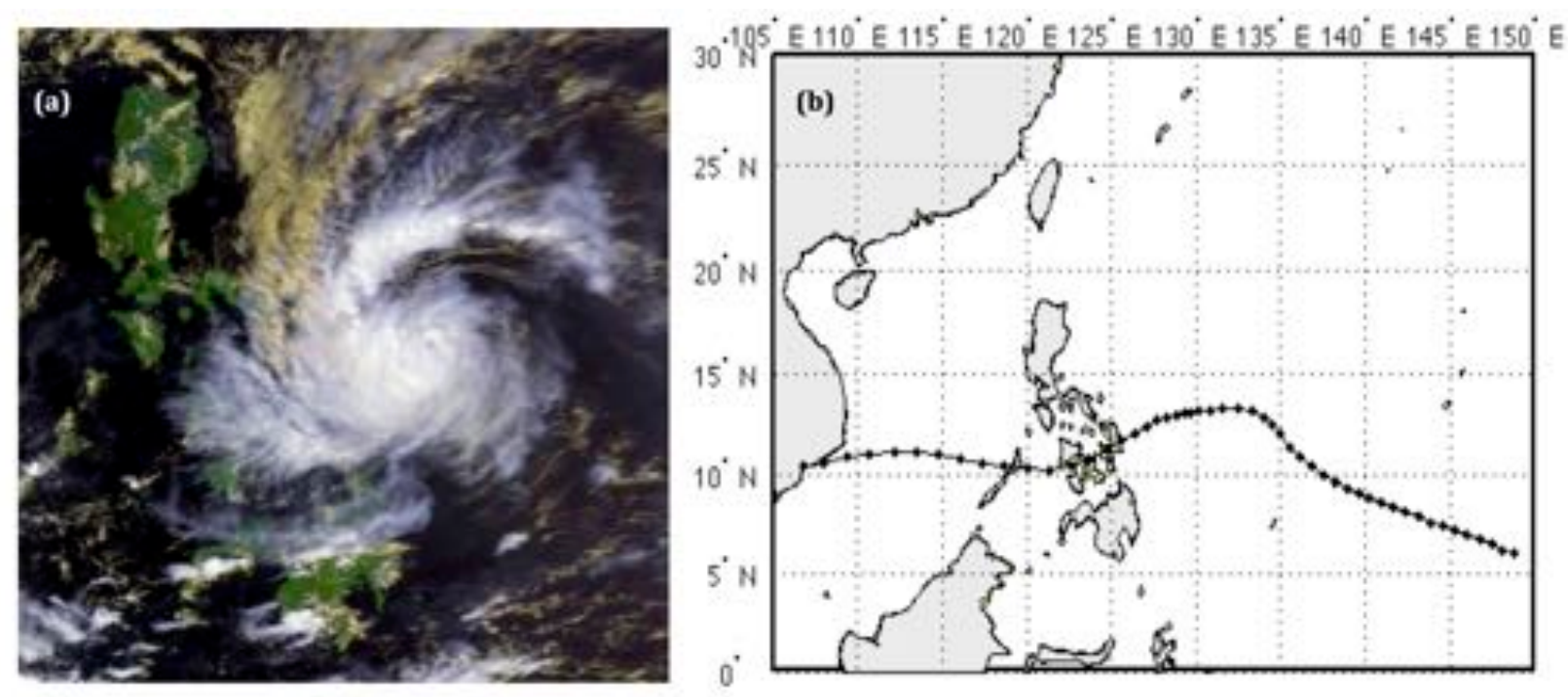

Figure 1. (a) Tropical Storm Thelma just before landfall in the Philippines on November 4, 1991.

637 Source: http://www.noaa.gov (b) Track of Tropical Storm Thelma (6-hourly positions). 


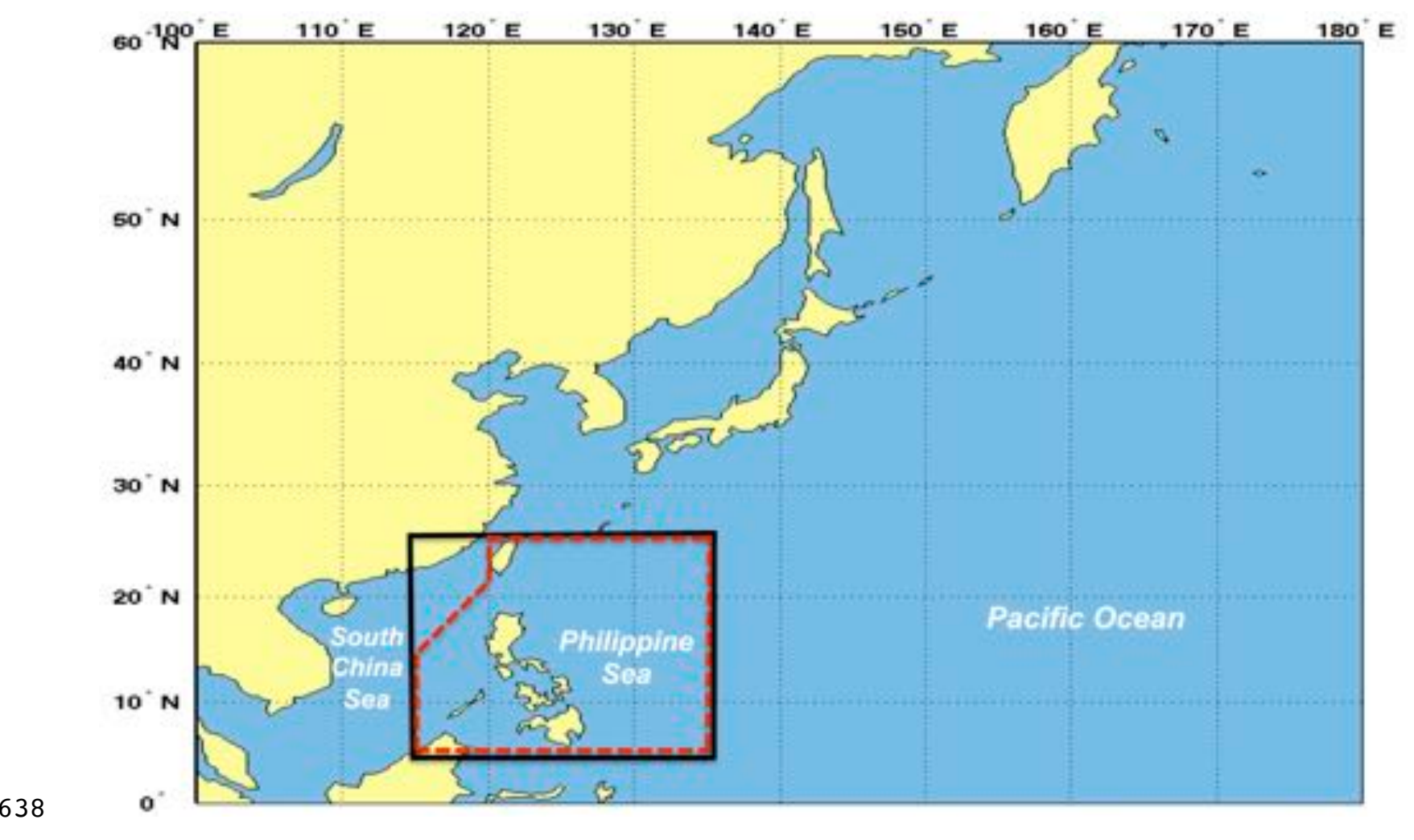

639 Figure 2 . The study region covers latitudes $5^{\circ}-25^{\circ} \mathrm{N}$ and longitudes $115^{\circ}-135^{\circ}$, shown as the

640 black inset and referred to here as the Philippine region, or domain. The irregular box (red 641 broken line) shows the Philippine Atmospheric, Geophysical and Astronomical Services 642 Administration (PAGASA) area of responsibility for tropical cyclones (TCs). PAGASA monitors 643 and forecasts TCs that affect the Philippines. This figure is adopted from Corporal-Lodangco et 644 al. (2016). 


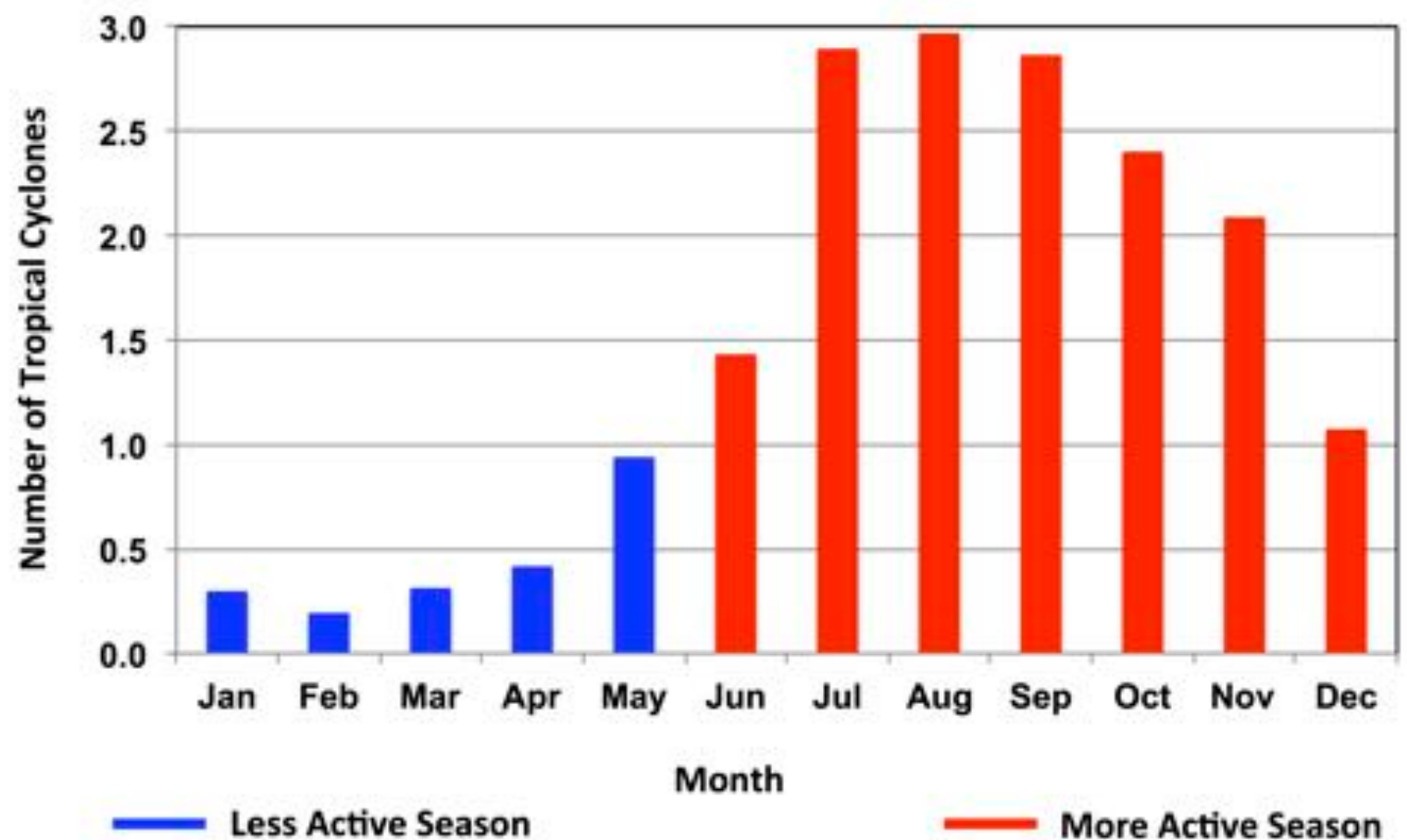

Figure 3. Mean monthly tropical cyclone (TC) counts in the Philippine region. The less active

647 season runs from January 1 to May 31, representing the relatively quiet phase of tropical 648 cyclone activity in the Philippine domain, during which there is a mean of less than one TC per 649 month. The more active season is from June 1 to December 31, with all monthly means 650 exceeding one. 

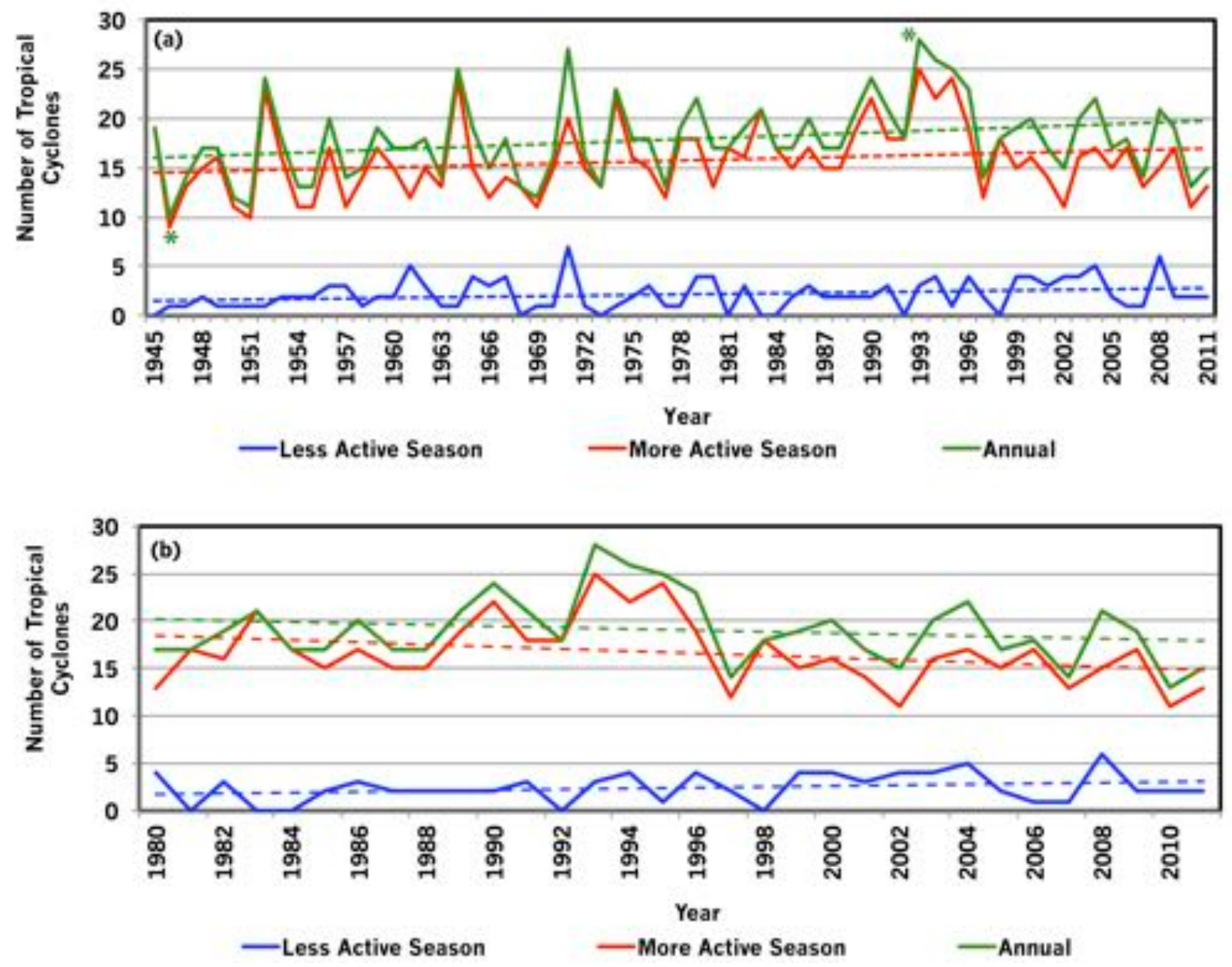

652 Figure 4. (a) Time series of annual number of tropical cyclones (green line) plotted against the 653 less active season (LAS - in blue line) and the more active season (MAS - in red line) TCs 654 during the period 1945-2011. The MAS dominates the mean annual TC numbers, accounting for 655 about $89 \%$ of the total. The linear trend lines are shown as dashed lines. The asterisks are the 656 minimum and maximum number of TCs during the period. (b) Same as 4a but for the satellite 657 era, defined here as 1980-2011. 


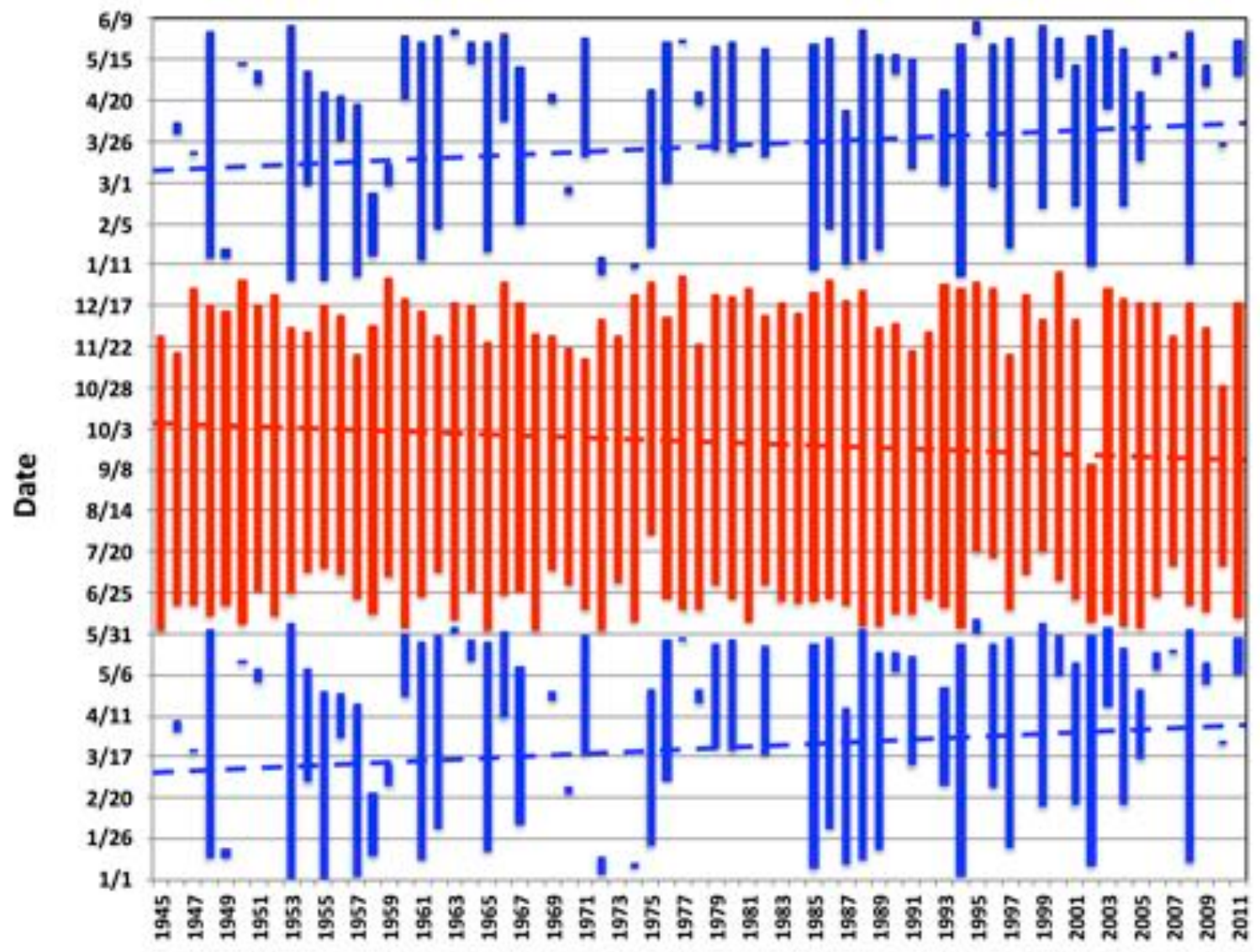

660 Figure 5. The year-to-year TC activity in the Philippine region showing alternating less active 661 season (LAS), quiescent periods, and more active season (MAS). The blue and red bars denote 662 the yearly season length of the less active season and the more active season, respectively. The 663 season start date (lower tip of the bar) is the day when the first TC is within the Philippine 664 domain. The end date of the season (upper tip of the bar) is defined as the day when the last TC 665 is inside the domain. The season length is end date minus start date. Dashed lines are linear trend 666 lines. 

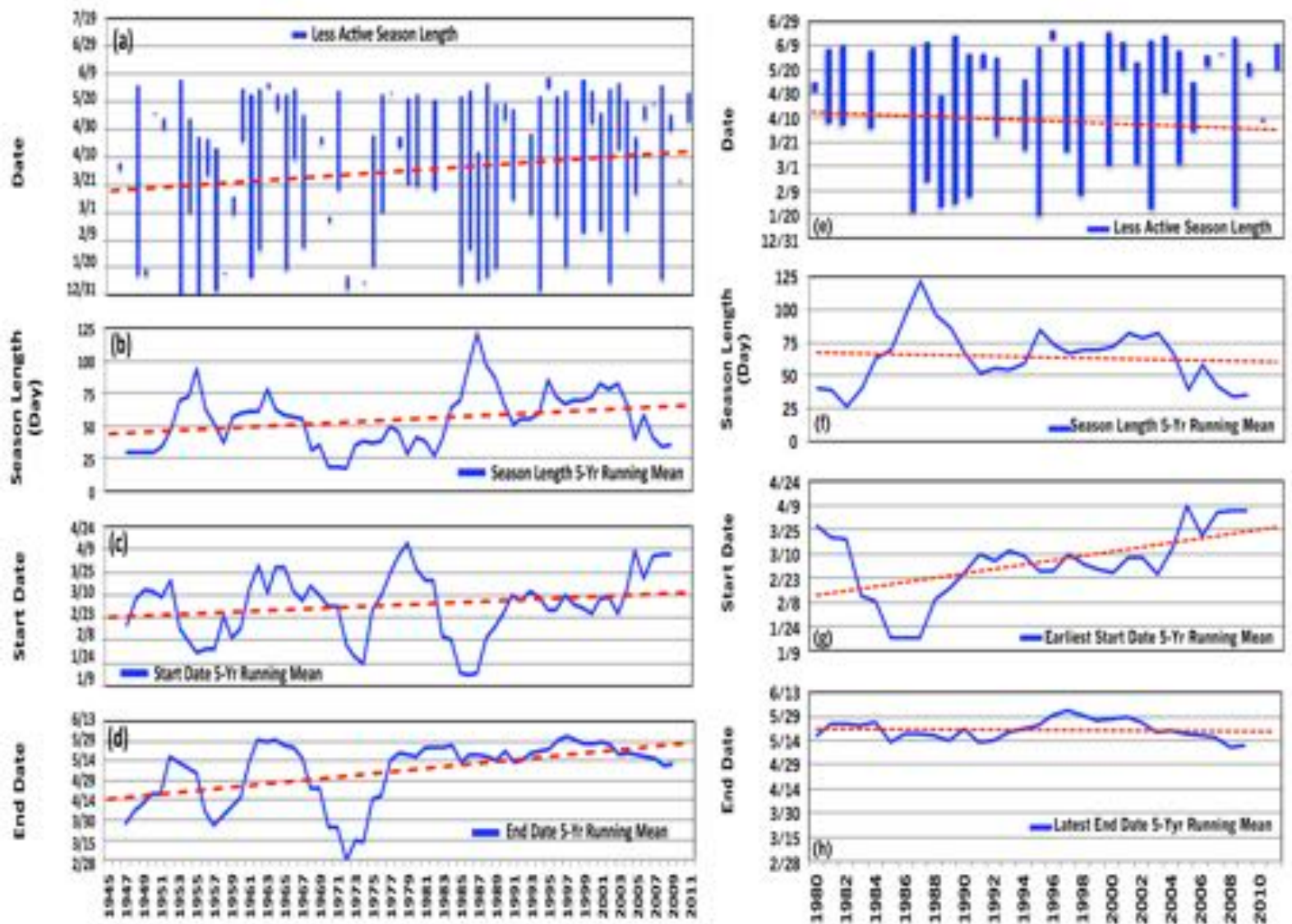

Year

Year

Figure 6. (a-d) The less active season (LAS) time series during the period 1945-2011. (a) The

669 length of LAS is the length of the bar in each year, (b) the 5-year running mean of LAS length,

670 (c) the 5-year running mean of LAS earliest start date, and (d) the 5-year running mean of LAS

671 latest end date. Dashed lines are linear trend lines. (e-h), same as (a-d), but during the satellite era 1980-2011. 

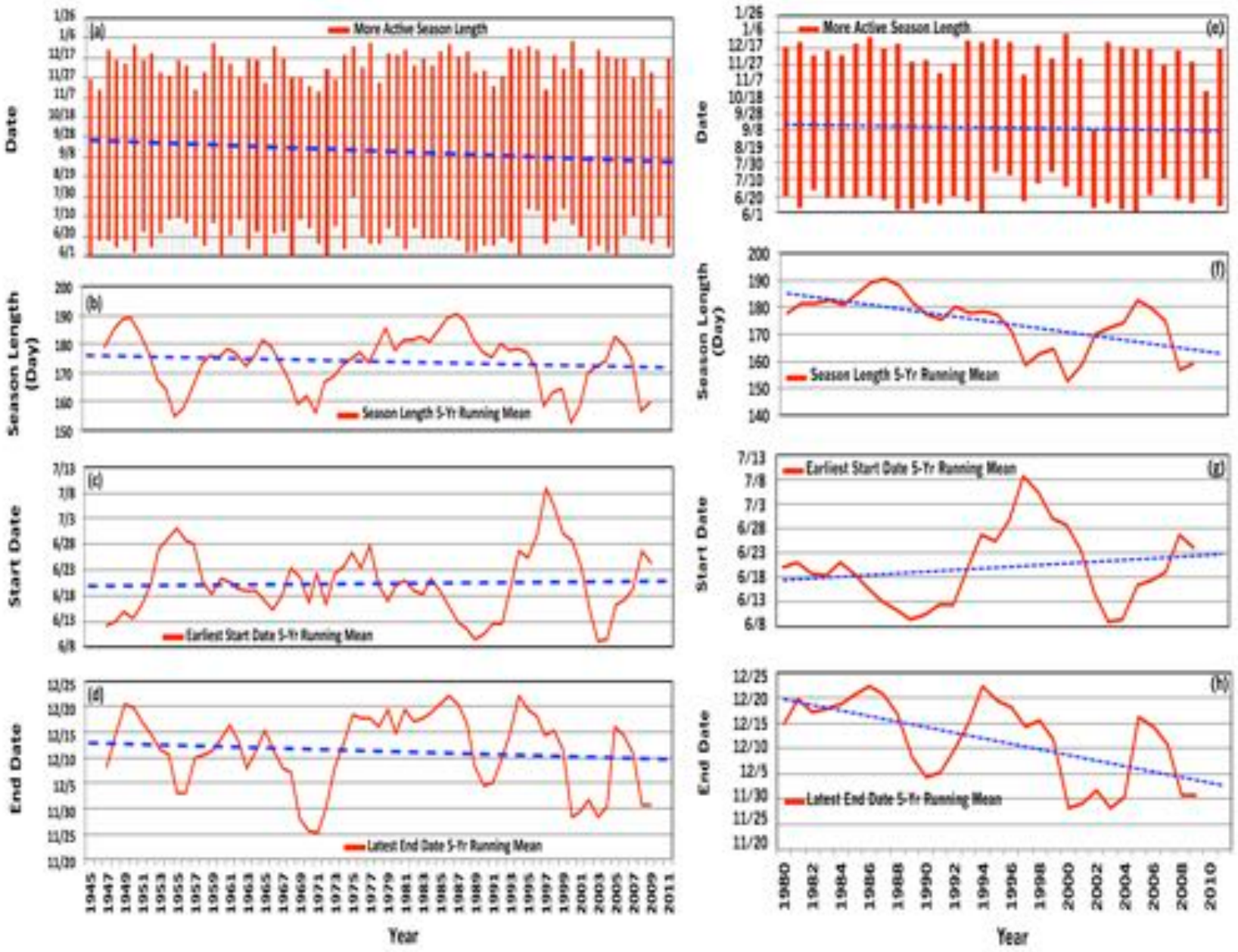

674 Figure 7. (a-d) The more active season (MAS) time series during the period 1945-2011. (a) The

675 yearly MAS length as represented by the length of each bar, (b) the 5-year running mean of MAS

676 length, (c) the 5-year running mean of MAS yearly earliest start date, and (d) the 5-year running

677 mean of MAS yearly latest end date. The dashed line for each graph is the trend line. (e-h), same 678 as (a-d), but during the satellite era 1980-2011. 

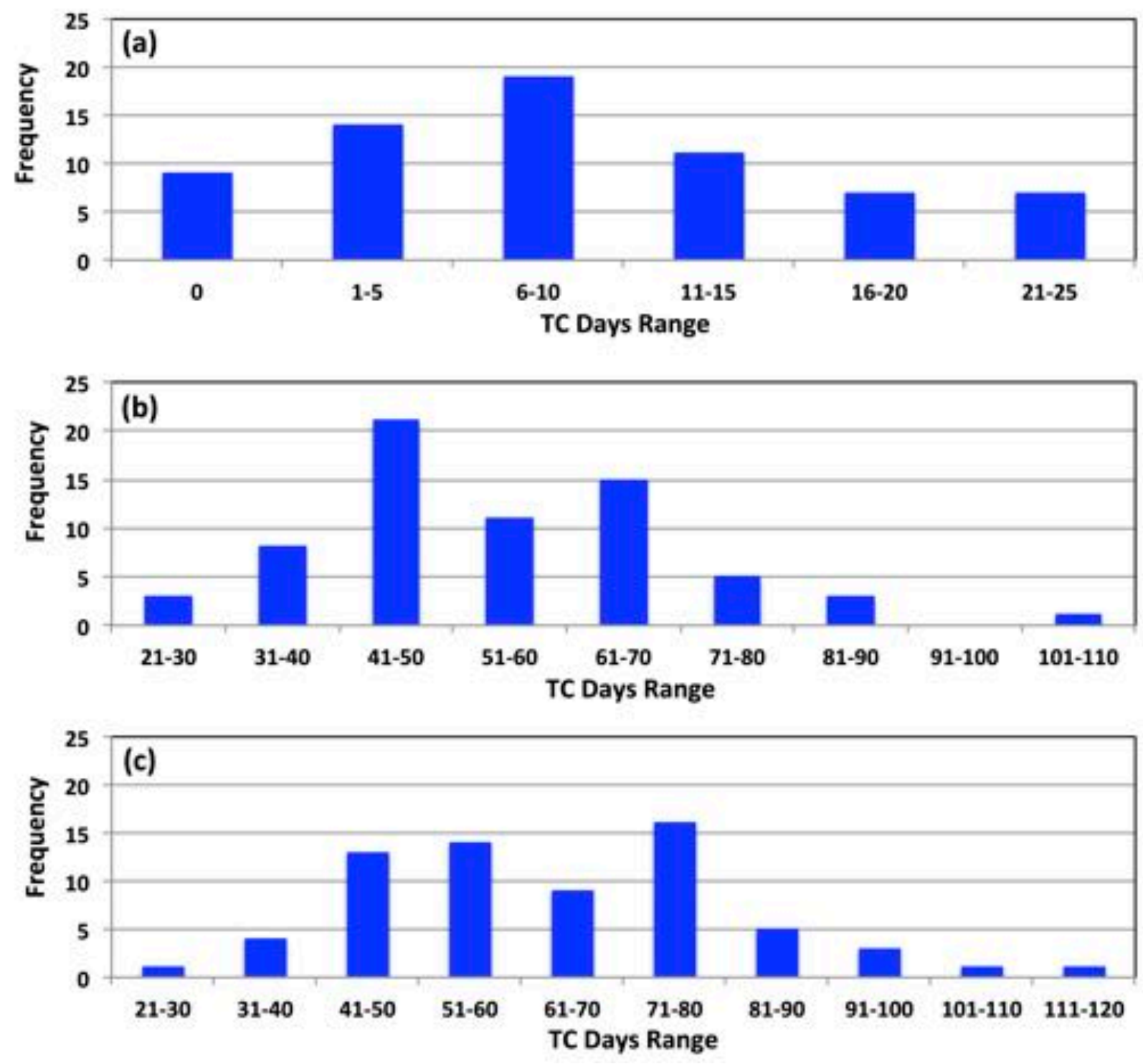

680 Figure 8. Frequency distribution of numbers of tropical cyclone (TC) days for (a) Less active 681 season (LAS), (b) More active season (MAS), and (c) annual total. A TC day is defined as 682 having at least one TC in the Philippine domain. The annual number of TC days is the sum of the 683 TC days from both the LAS and the MAS. 

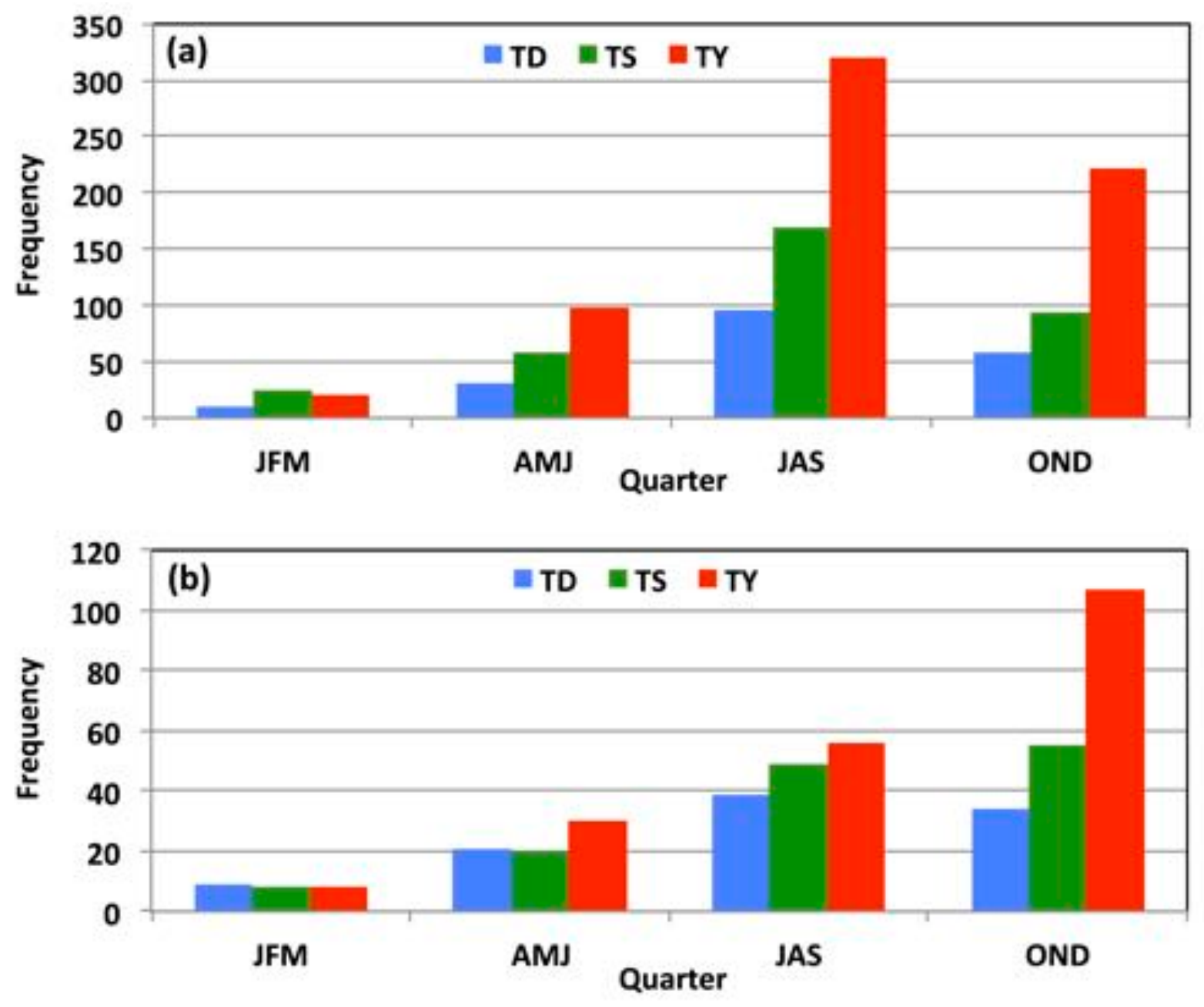

685 Figure 9. (a) Tropical cyclone intensity classification by quarter; tropical depression (TD), 686 tropical storm (TS), and typhoon (TY), and (b) Same as (a), but for landfall quarterly intensity 687 classification count. 


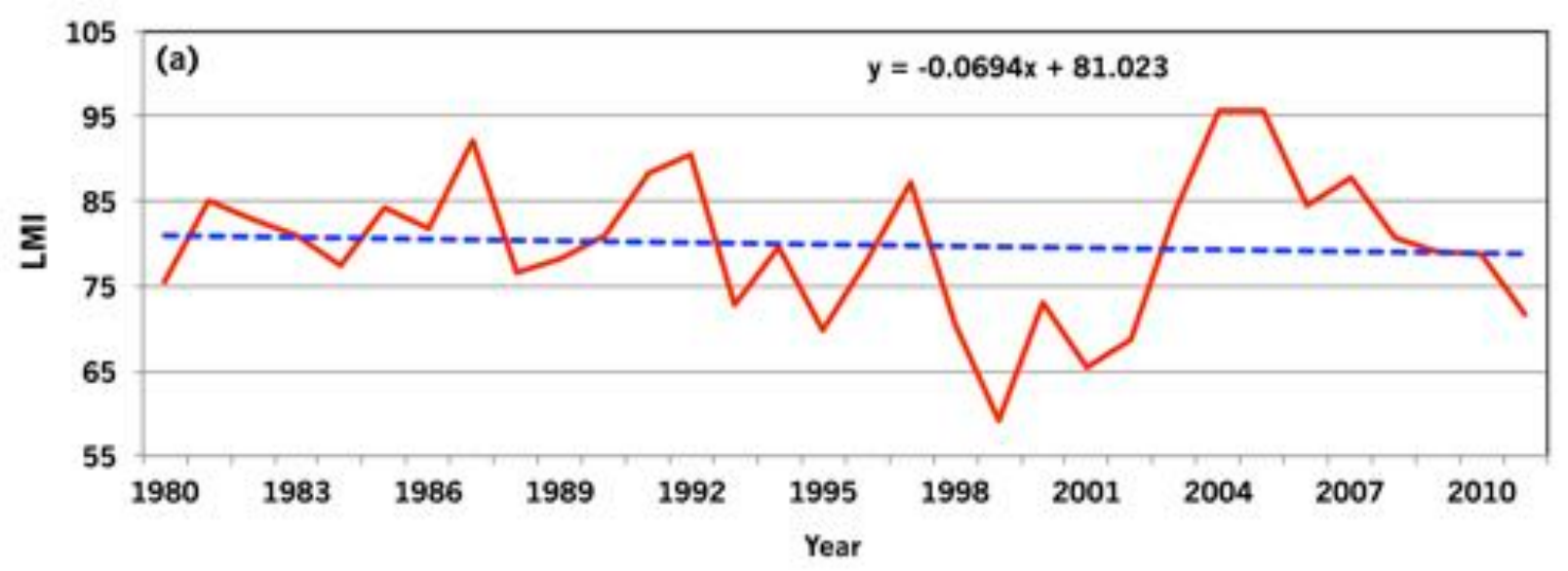

- Annual Ave LMI

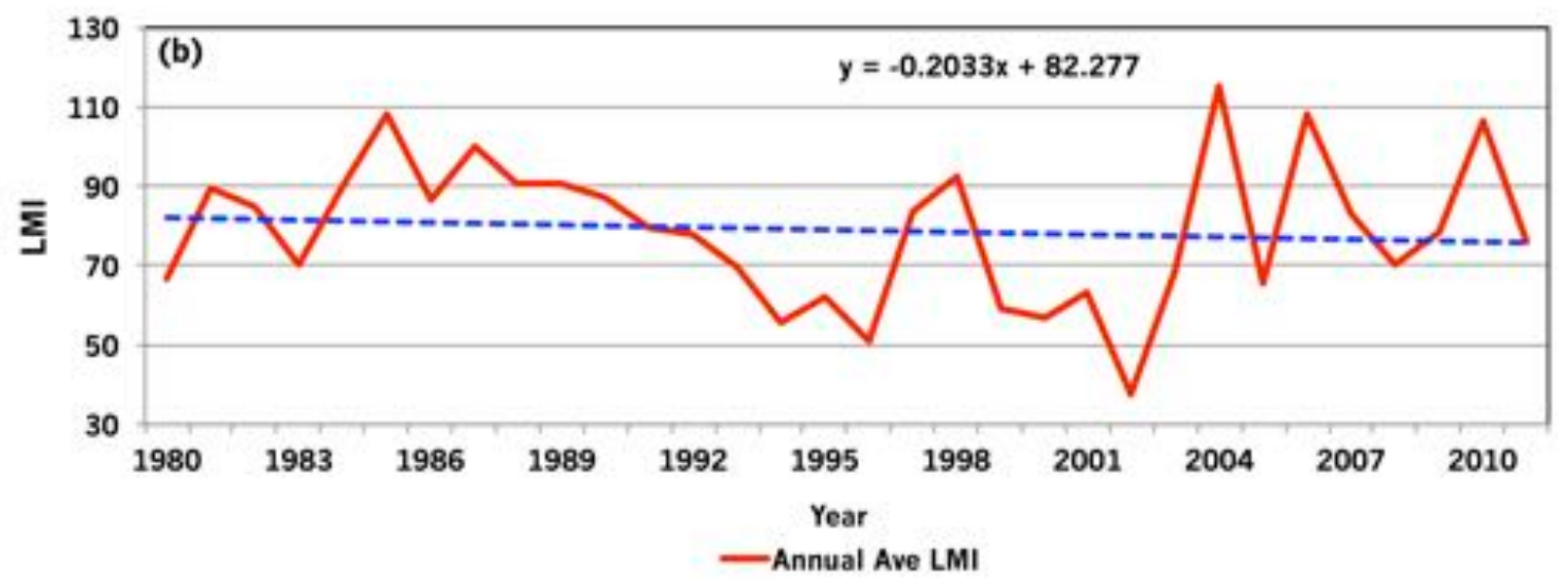

688

689 Figure 10. (a) Annual average of lifetime maximum intensities for all tropical cyclones (TCs)

690 during the satellite era. (b) Same as (a) but for landfalling TCs. 

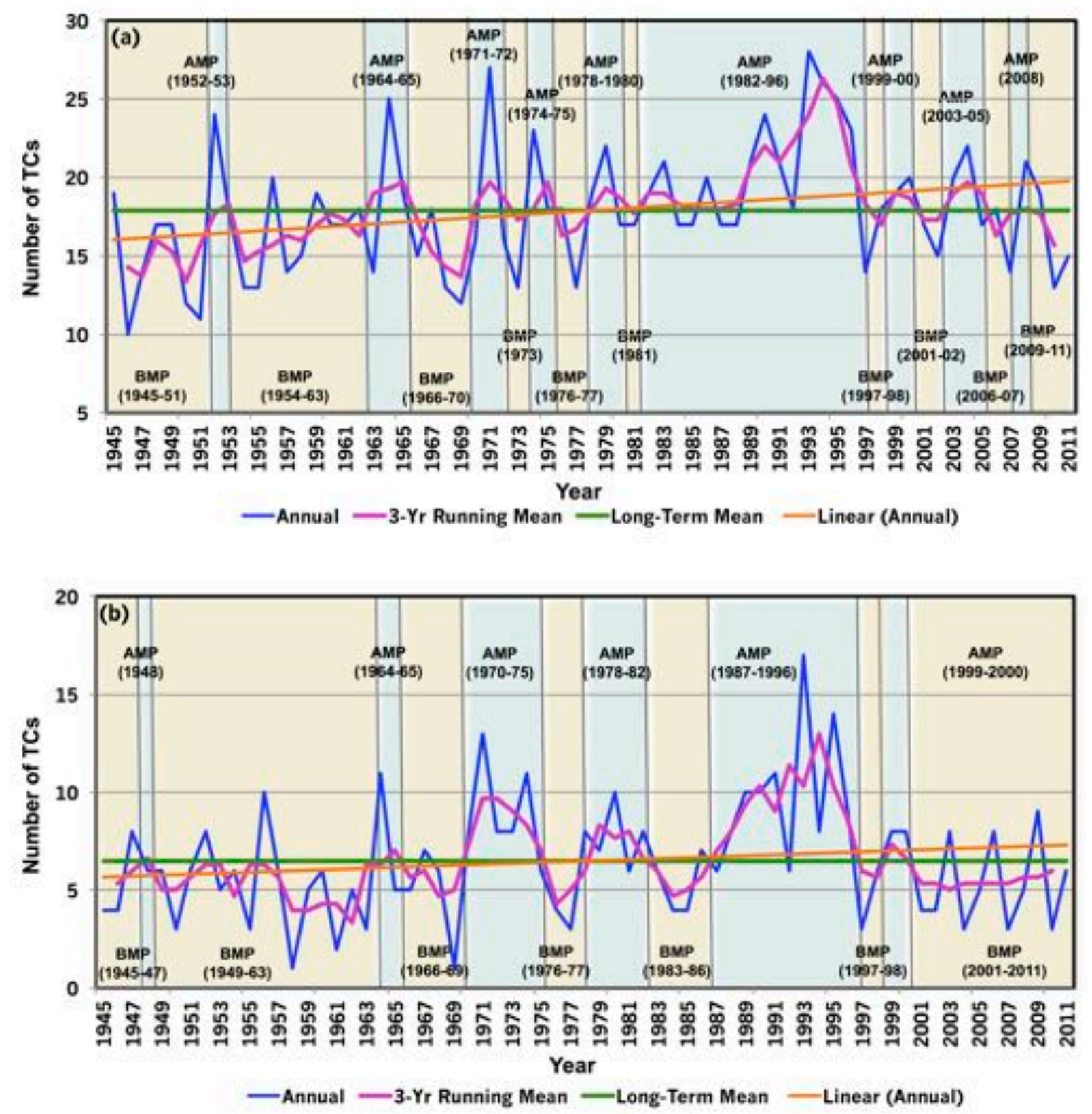

692 Figure 11. Philippine interannual and interdecadal variations in the frequencies of (a) all tropical

693 cyclones (TCs) and (b) landfalling TCs, over the 1945-2011 period. Years with 3-year running 694 means below the long-term mean of 17.9 (6.5) for all TCs (landfalls) are part of the below mean 695 period (BMP), and all years with 3-year running means above the long-term mean are included 696 in the above mean period (AMP). Orange line is a linear trend line. 


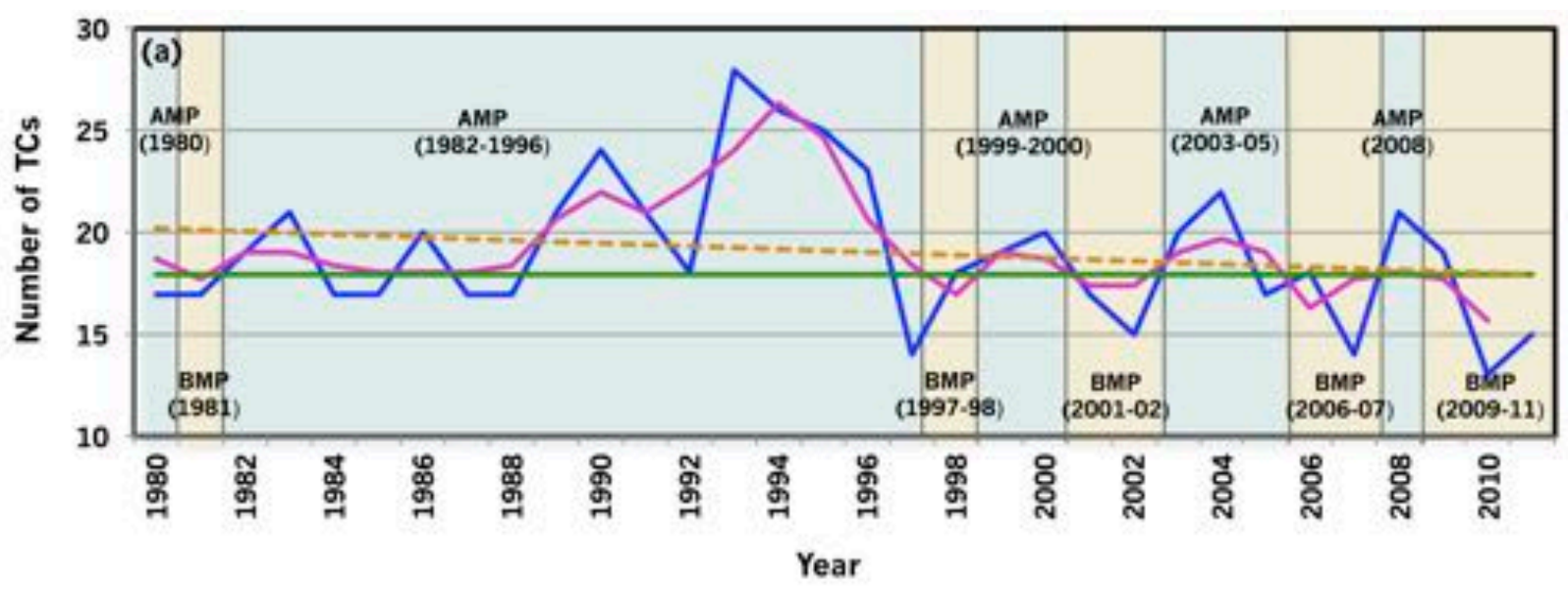

— Annual TCs — 3-Yr Running Mean —-Long-Term Mean ---Linear (Annual TCs)

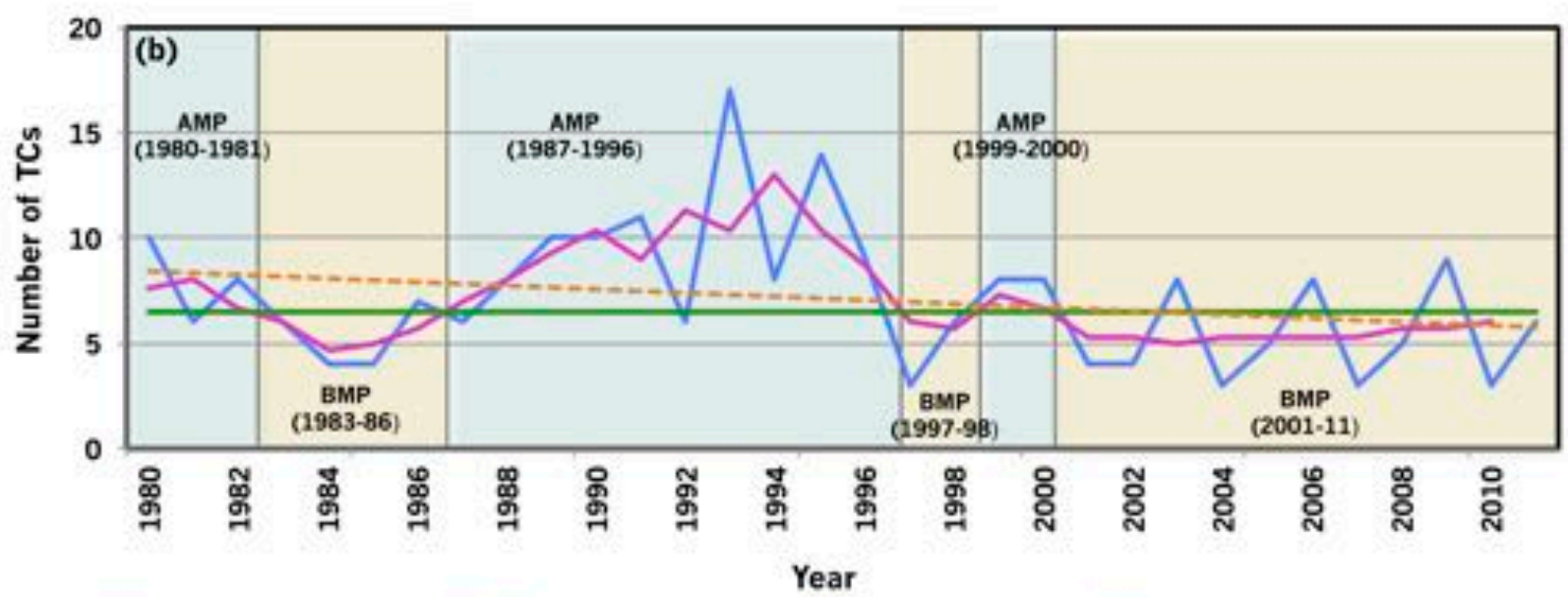

Figure 12. Interannual and interdecadal variations in the frequencies of (a) all Philippine tropical cyclones (TCs) and (b) landfalling TCs during the satellite era 1980-2011. 


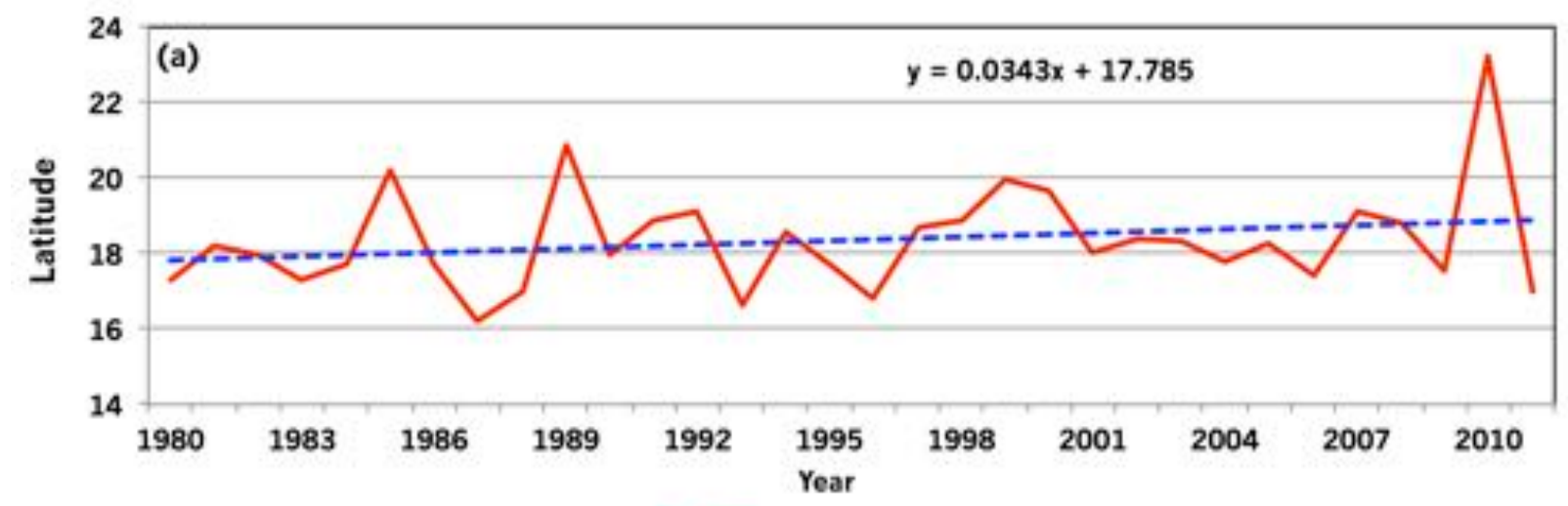

-LMI Ave Latitude

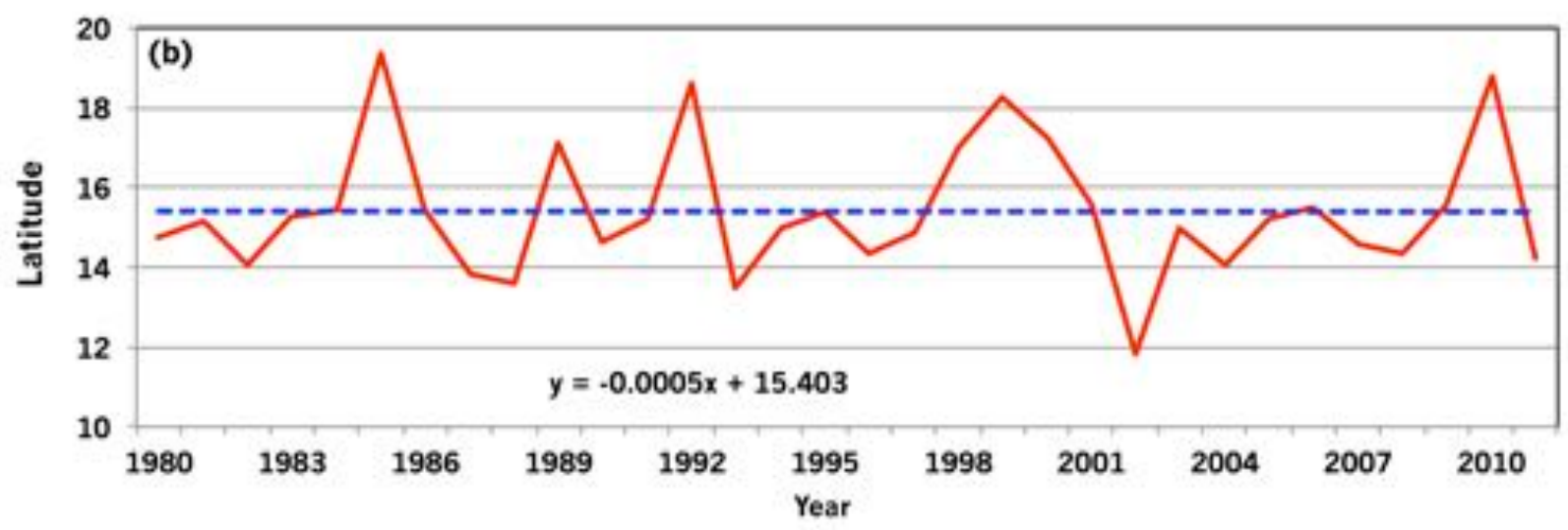

701 Figure 13. (a) Annual average latitude of lifetime maximum intensity (LMI) during the satellite 702 era for all tropical cyclones (TCs). (b) Same as (a) but for landfalling TCs. 

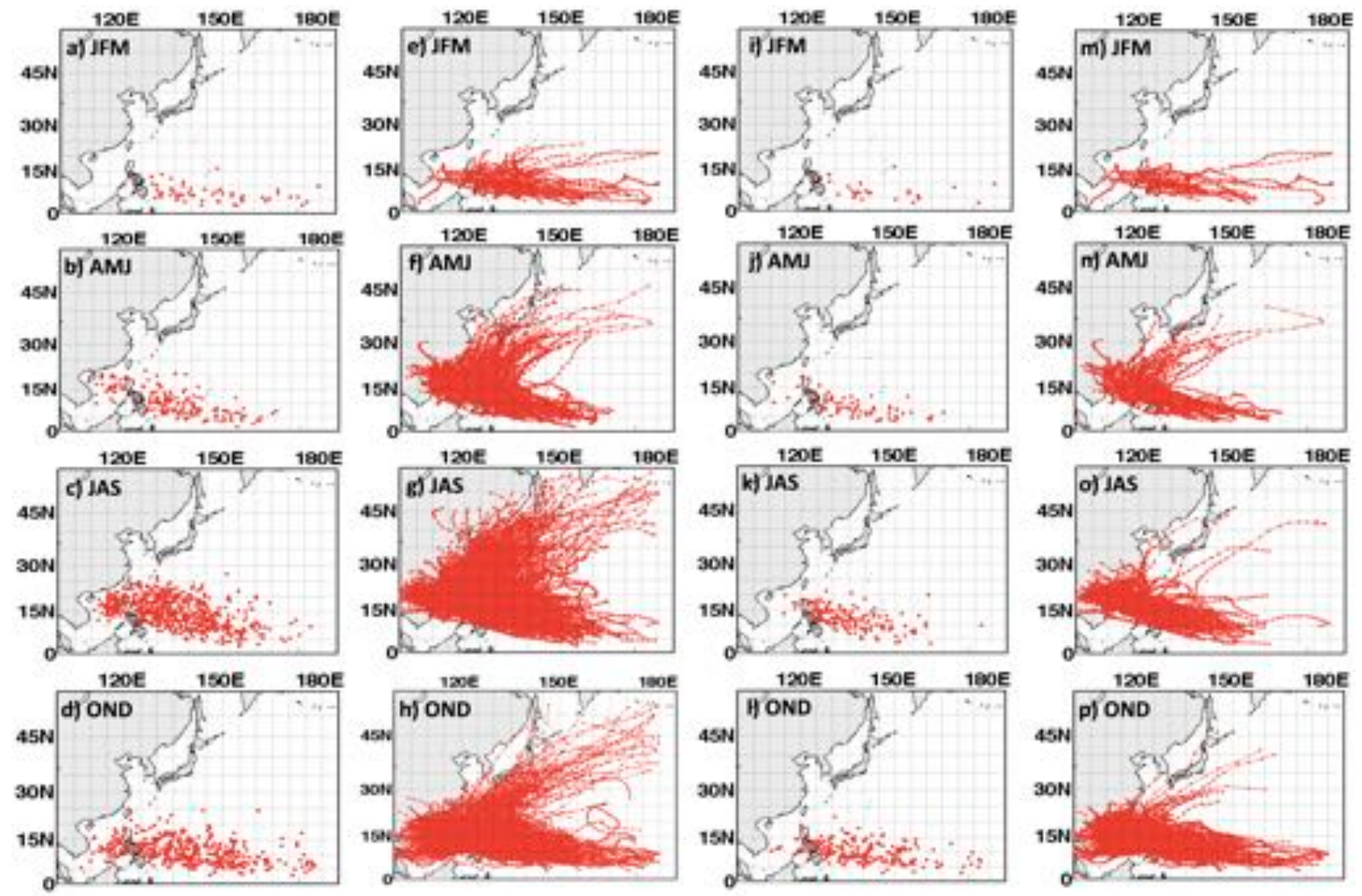

704 Figure 14. (a-d) Quarterly variations in genesis positions of all tropical cyclones (TCs), (e-h)

705 quarterly tracks of all TCs, (i-l) quarterly genesis positions of landfalling TCs, and (m-p)

706 quarterly tracks of landfalling TCs. 
(a)

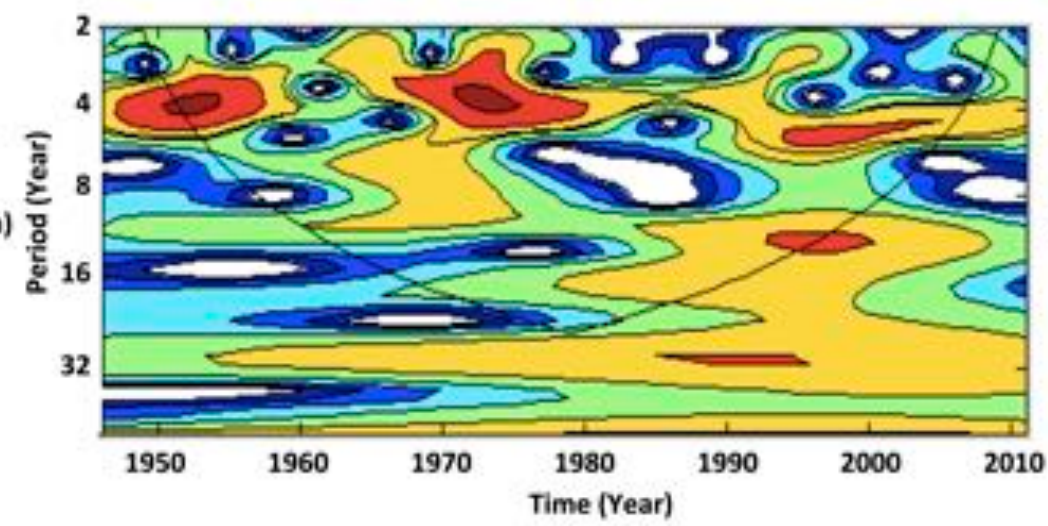

(b)

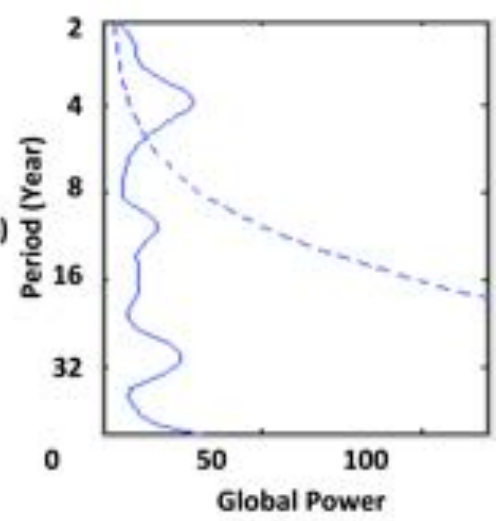

708 Figure 15. (a) Wavelet analysis of the Philippine tropical cyclone time series; the region above 709 the black curve indicates the $95 \%$ level of confidence. (b) The corresponding global wavelet 710 spectrum; the dashed blue line is the $95 \%$ level of confidence. Note the peaks in the $2-7$ year, $711 \quad 10-12$ year and 28-32 year periods. 

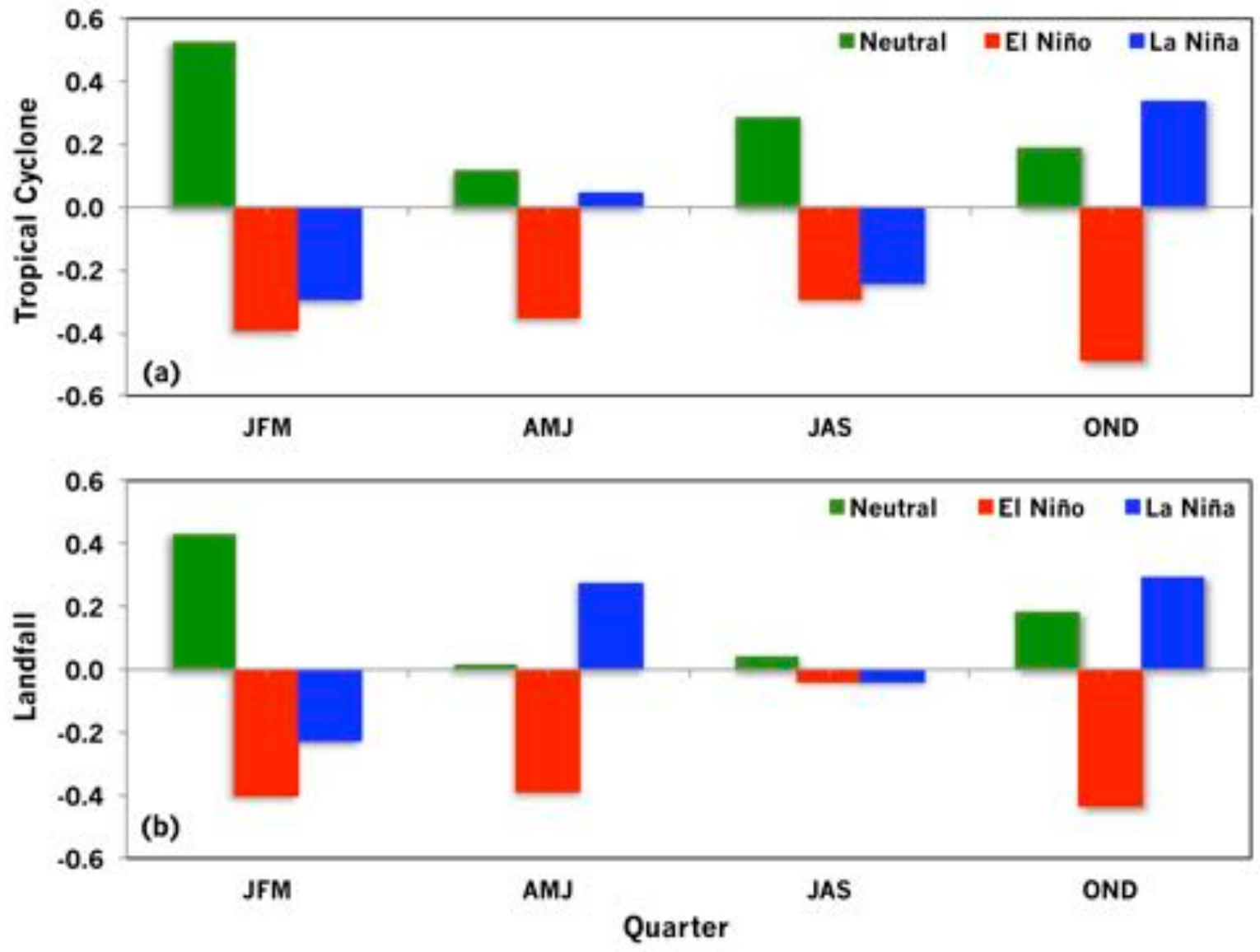

713 Figure 16. The quarterly tropical cyclone-El Niño Southern Oscillation relationship (a) 714 Standardized quarterly TC mean during Neutral, El Niño and La Niña phases, (b) Same with (a) 715 but for standardized TC landfall mean. This figure is adopted from Corporal-Lodangco et al. 716 (2016). 